Portland State University

PDXScholar

6-12-1981

\title{
Burnout: Multi-Dimensional Study of Alienation Among Social Service Workers in the Willamette Valley
}

\author{
Sally Carignan \\ Portland State University \\ John Deihl \\ Portland State University \\ Judy Harris \\ Portland State University \\ Jay Jones \\ Portland State University \\ Bonnie Rothman \\ Portland State University \\ Follow this and additional works at: https://pdxscholar.library.pdx.edu/open_access_etds \\ Part of the Social Work Commons \\ Seepextrageforadditional authors
}

\section{Recommended Citation}

Carignan, Sally; Deihl, John; Harris, Judy; Jones, Jay; Rothman, Bonnie; Ullmann, Sabrina; WeinbergGordon, Beth; Weter, Phyllis; Whitty, Patricia; and Wilson, Loretta, "Burnout: Multi-Dimensional Study of Alienation Among Social Service Workers in the Willamette Valley" (1981). Dissertations and Theses. Paper 3500.

https://doi.org/10.15760/etd.5383

This Thesis is brought to you for free and open access. It has been accepted for inclusion in Dissertations and Theses by an authorized administrator of PDXScholar. Please contact us if we can make this document more accessible: pdxscholar@pdx.edu. 


\section{Author}

Sally Carignan, John Deihl, Judy Harris, Jay Jones, Bonnie Rothman, Sabrina Ullmann, Beth WeinbergGordon, Phyllis Weter, Patricia Whitty, and Loretta Wilson 
BURNOUT: A MULTI-DIMENSIONAL STUDY OF ALIENATION AMONG SOCIAL SERVICE WORKERS IN

THE WILLAMETTE VALLEY

\author{
by \\ SALLY CARIGINAN \\ JOHN DEIHL \\ JUDY HARRIS \\ JAY JONES \\ BONNIE ROTHMAN \\ SABRINA ULLMANN \\ BETH WEINBERG-GORDON \\ PHYLLIS WETER \\ PATRICIA WHITTY \\ LORETTA WILSON
}

A research practicum submitted in partial fulfillment of the requirements for the degree of

MASTER OF SOCIAL WORK

Portland State University

1981 
TO THE OFFICE OF GRADUATE STUDIES AND RESEARCH:

The Advisor approves the practicum of Sally Carignan, John Deihl, Judy Harris, Jay Jones, Bonnie Rothman, Sabrina Ullmann, Beth Weinberg-Gordon, Phyllis Weter, Patricia Whitty, and Loretta Wilson, presented June 12, 1981.

John F. Longres, Advisor 


\section{ACKNOWLEDGMENTS}

We wish to acknowledge and thank social service workers in the Greater Portland Metropolitan area, who took the time and effort to answer our questionnaire.

We are particularly grateful to the Oregon Chapter of the National Association of Social Workers for their financial contribution and for providing us a list of the Oregon Chapter mailing list.

We extend our gratitude to our advisor, John Longres, for his patience, assistance, and sense of humor. 
TABLE OF CONTENTS

PAGE

ACKNOWLEDGMENTS . . . . . . . . . . . . . . . . iii

LIST OF TABLES . . . . . . . . . . . . . . . . . . . vii

LIST OF FIGURES . . . . . . . . . . . . . . . . . . . $\mathrm{x}$

INTRODUCTION . . . . . . . . . . . . . . . . . . 1

CHAPTER

I REVIEW OF THE LITERATURE . . . . . . . . . 4

The Burnout Syndrome--The Subjective
Expression of Alienation . . . . 4

Alienation: A Subjective Experience or a Social-Structural Condition? . . . 9

Empirical Studies on Work Alienation . . 13

Objective of Study . . . . . . . . . . 23

II METHODOLOGY . . . . . . . . . . . 25

The Variables Examined . . . . . . . . 25

Statistical Analysis . . . . . . . . 29

Gamma . . . . . . . . . . . . . . 29

Sent Sample . . . . . . . . . . . . 31

Returned Sample . . . . . . . . . 32

Limitations of the Study . . . . . . . 37

Ethical Issues . . . . . . . . . . . . . 40 
III DESCRIPTION OF THE VARIABLES . . . . . . 42

Introduction . . . . . . . . . . . 42

Structural Alienation .. . . . . . . 42

Societal Alienation (Independent Variable)............ . 48

Subjective Alienation (Dependent
Variable) . . . . . . . . . 52

Social Reality... . . . . . . . 56

Summary . . . . . . . . . . . 60

IV THE RELATIONSHIP BETWEEN STRUCTURAL/

SOCIETAL ALIENATION AND SUBJECTIVE ALIENATION . . . . . . . . . . . . 63

Introduction . . . . . . . . . . 63

Structural Alienation by Subjective Alienation ............ . 64

Societal Alienation and Subjective Alienation . . . . . . . . . . . .

V STRUCTURAL ALIENATION VERSUS SOCIETAL ALIENATION . . . . . . . . . . . . . 69

Introduction . . . . . . . . . 69

Structural versus Societal . . . . . 70

Summary . . . . . . . . . . . . 80

VI SOCIAL "REALITY": AN INTERVENING VARIABLE . 82

Introduction . . . . . . . . . . 82

Negative Social Reality . . . . . . 84

Ambiguous Social Reality . . . . . . 84

Positive Social Reality . . . . . . . 88

Societal Alienation and Social Reality . 88

Summary . . . . . . . . . . 93 
CHAPTER

PAGE

VII DISCUSSION

Introduction . . . . . . . . . . . . . 96

Conclusions . . . . . . . . . . . . . 96

BIBLIOGRAPHY . . . . . . . . . . . . . . . 103

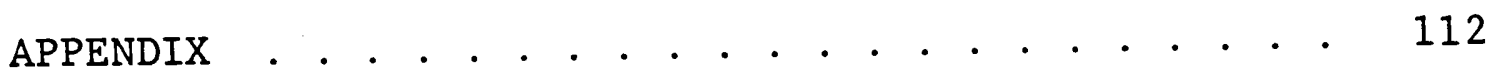




\section{LIST OF TABLES}

\section{TABLE}

I Job Titles of Social Service Respondents . .

II Chief Duties of Social Service

Respondents .

III Type of Agency . . . . . . . . . . . . . . . 36

IV Structural Alienation: Frequency of

Responses in Percent . . . . . . . . .

$\mathrm{V}$ Societal Alienation: Frequency of

Responses in Percent.

VI Subjective Alienation: Frequency of

Responses in Percent . . . . . . . . . .

VII Social "Reality" and Hypothesized

Alienation: Frequency of Responses

in Percent. .

VIII Structural Alienation by Subjective

Alienation: Gamma Coefficient . . . . .

IX Societal Alienation by Subjective

Alienation: Gamma Coefficient . . . .

$\mathrm{X}$ Structural Alienation by Subjective

Alienation: Controlling for "Choice of Clients"--Societal Alienation . . . . . 
XI Structural Alienation by Subjective

Alienation: Controlling for "Severe

Economic Problems"--Societal Alienation .

XII Structural Alienation by Subjective

Alienation: Controlling for "Stable

Funding"--Societal Alienation . . . . .

XIII Structural Alienation by Subjective

Alienation: Controlling for "Limited

Community Resources"--Societal

Alienation . . . . . . . . . . . . . . . 74

XIV Societal Alienation by Subjective

Alienation: Controlling for "Access

to Administration"--Structural

Alienation . . . . . . . . . . . . .

XV Societal Alienation by Subjective

Alienation: Controlling for "Unclear

Expectations"--Structural Alienation. .

XVI Societal Alienation by Subjective
Alienation: Controlling for "Learn
New Things"--Structural Alienation . . .

XVII Structural Alienation by Subjective

Alienation: Controlling for "Few

Opportunities for Advancement"--

Social Reality . . . . . . . . . . . 
TABLE

XVIII Structural Alienation by Subjective
Alienation: Controlling for "Fair

Salary"--Social Reality . . . . . . . . .

XIX Structural Alienation by Subjective

Alienation: Controlling for "Job as

Good as Any"--Social Reality . . . . . . .

XX Societal Alienation by Subjective

Alienation: Controlling for "Few

Opportunities for Advancement"--

Social "Reality" . . . . . . . . . . . . .

XXI Societal Alienation by Subjective
Alienation: Controlling for "Fair

Salary"--Social "Reality" . . . . . . .

XXII Societal Alienation by Subjective

Alienation: Controlling for "Job as

Good as Any"--Social "Reality" . . . . .

XXIII Age of Respondents . . . . . . . . . . . 117

XXIV Length of Time Employed in Social Services • 117

XXV Length of Time Employed at Present

Position . . . . . . . . . . . . . . . . 


\section{LIST OF FIGURES}

FIGURE

PAGE

1. Respondents in Private and Public Practice. . 34

2. Education of Respondents . . . . . . . . . 38

3. Gender of Respondents . . . . . . . . . . . 39

4. Full- or Part-time Employment in Social

Services . . . . . . . . . . . 116 


\section{INTRODUCTION}

In recent years there has been a growing surge of interest and recognition in the prevalence of "burnout" among social service workers. Burnout has been defined as to "fail, wear out, or become exhausted by excessive demands on energy, strength or sources" (Freudenberger, 1975, p. 73). From this definition, one can ascertain that this depletion of capacities is of critical concern to both the workers and administrators in the social services and the clients whom they serve.

The manifestation of burnout has been reported to be that of cynical and negative attitudes and involves a loss of concern and unresponsiveness to the problems and needs of others--an emotional withdrawal (Daley, 1979). This subjective description of burnout bears a striking and undeniable resemblance to the psychological aspects of Marx's theory of alienation. Thus, to the writers of this study, burnout describes the subjective experience of alienation and the ways in which estrangement from self and others (two aspects of alienation according to Marx) are expressed. Burnout thus seems limited in its utility for understanding this phenomenon, while Marx's theory of alienation encompasses not only the psychological dimensions of burnout, but the structural aspects as well. Therefore, the concept 
of alienation will be utilized in this study in an attempt to further knowledge in this area by using the more relevant and encompasing theory of alienation as it applies to the work place.

In a profession such as social work, where one is responsible for dealing with the ills of society and meeting the needs of other individuals, such emotional detachment and estrangement from others is antithetical to the purpose of the field and eminently destructive to those seeking and needing assistance. With the current push for accountability, factors such as burnout or alienation from one's work become of crucial importance. In addition, burnout leads to a high rate of absenteeism and job turnover (Minihan, 1980). This too decreases cost effectiveness and the quality of service, matters of extreme concern in a field designed to serve the needs of individuals in society and to do so on limited funds and resources.

Thus, alienation is of paramount importance to the field of social services and can no longer be ignored or relegated to a back seat in terms of study and research. Current literature in the field of social work deals only with the subjective expression of alienation; it has omitted linking the psychological with the social-structural aspects of alienation: indeed, with linking burnout to alienation itself. This study proposes to begin to fill this gap. What conditions in the structure of the work place and/or 
society cause or are correlated with the expression of alienation? It is this question which we endeavor to pursue. 


\section{CHAPTER I}

\section{REVIEW OF THE LITERATURE}

In this review of the literature, we will focus primarily on the empirical research which emphasizes the social structural contexts of work alienation with the hope of identifying some of the common structural causes of work alienation. However, because of the vast amount of literature on the "burnout syndrome" of social service workers, we find it difficult to ignore the studies describing the subjective experiences of alienation; therefore, we will briefly discuss this existing literature. Our discussion will focus on the following areas:

(1) Existing literature dealing with the "burnout" syndrome

(2) Theoretical literature dealing with the question of whether alienation is primarily a subjective psychological phenomenon or a social-structural condition

(3) Empirical studies of work alienation THE BURNOUT SYNDROME--THE SUBJECTIVE EXPRESSION OF ALIENATION

Burnout has been used to describe a number of affective states and behavioral phenomena which in the past have been identified with job dissatisfaction and/or stress. 
Pines and Maslach (1978, p. 233) have defined burnout for social service workers :

. . as a syndrome of physical and emotional exhaustion, involving the development of negative selfconcept, negative job attitudes and loss of concern and feeling for clients.

Edelwich and Brodsky (1980, p. 14) define burnout as:

- . a progressive loss of idealism, energy, and purpose experienced by people in the helping profession as a result of the conditions of their work. (Italics ours.)

Daley terms it a "reaction to job-related stress" (1979, p. 375).

While the definitions of burnout are many and varied, most authors agree that it is an affective state due to work-related stress and that it unfolds as a process with a progression of stages. Daley (1979) relates the stages of burnout to that of human behavior under stress. First there is an "alarm state" where an individual's energies are all expended in an effort to manage stress. This state may be likened to that of detached concern identified by Maslach (1976). Finally, this stage may give way to exhaustion in which adaptive coping abilities break down.

Edelwich and Brodsky (1980) refer to the dynamic process of burnout as stages of disillusionment. These stages are (1) enthusiasm, (2) stagnation, (3) frustration, and (4) apathy. This process of disillusionment is not viewed as inevitable or as a strict linear progression. Thus, the cycle can be interrupted at any point with an appropriate 
intervention, although the last stages are seen as more resistant to intervention than the beginning stages.

Burnout has been seen to be a particularly acute problem for those in protective services (Daley, 1979), child care work (Freudenberger, 1977), and those working with chronic mental patients (Mendel, 1979). In a recent study among child welfare workers (Lawton \& Magarel1i, 1980), 96 percent of the social workers viewed their jobs as stressful with 64 percent of these workers claiming stress-related health problems due to their work. In addition, 73 percent of these people plan to quit their jobs, 53 percent within one year. This study exemplifies the prevalence of worker burnout within the field of social work.

The effects of burnout are felt by the worker and the clients $\mathrm{s} /$ he serves as well. Symptoms of burnout include cynicism, negativism, inflexible and rigid thinking, an emotional distancing from the client, boredom with one's work, a sense of helplessness and hopelessness, and frequently the home life of the worker deteriorates (Freudenberger, 1977). Burnout has been seen as a key factor in low worker morale, absenteeism, and high job turnover; furthermore, burnout has been correlated with alcoholism, mental illness, marital conflict, and suicide (Maslach, 1976). In addition, many stress-related health problems such as ulcers, headaches, insomnia, and depression are correlated with the burnout syndrome (Lawton \& Magarel1i, 1980). Thus, the 
impacts of burnout are many and varied, resulting in a negative effect upon the social service worker, the agency and clients s/he serves, and on society as well.

All of these symptoms are affective, behavioral, and/or physical responses to the conditions of one's work. As Schacht has stated, alienation from one's work can mean any or all of the following:

(1) dissatisfaction with one's job, (2) experience of work as not being intrinsically rewarding,

(3) experience of being insufficiently self-directed, meaningful and self-expressive. (1971, p. 171)

From this perspective (of alienation from one's work), burnout can be seen as the subjective or psychological aspect of alienation. As stated by Maslach:

For social welfare workers, one of the major signs of burn-out was the transformation of a person with original thought and creativity on the job into a mechanical, petty, bureaucrat. (1976, p. 18)

This manifestation of burnout fits well with Schacht's depiction of work alienation. To the burned-out or alienated worker, work has become unfulfilling and meaningless; thus, work has lost its value. Since "the value of work, as a contributor to our well-being, is a function of its ability to provide opportunities for achievement and growth," these conditions for fulfillment would appear to be lacking in the structure of the work place, thus resulting in alienation from one's work and the subjective experience of burnout (Muldoon, 1980, p. 113). 
Although definitions of burnout refer to the conditions of one's work (Edelwich \& Brodsky, 1980), most of the solutions sought have been focused upon an individual rather than a structural level. Yoga, physical exercise, classes in stress management, furthering one's education, worker support networks, times out, job sharing and rotation, and staff retreats are often cited as remedies for burnout (Pines \& Maslach, 1978; Daley, 1979). Edelwich and Brodsky (1979) suggest utilizing concepts from Reality Therapy and Rational Emotive Therapy. They encourage the worker to:

. . work from an acknowledgement of existing conditions rather than an idealized reconstruction of the helping relationship, social service institutions, or society as a whole. (Ibid., p. 30)

The stress here is upon accepting reality (or the status quo) and assuming responsibility for oneself. This is a sad conclusion after their hopeful definition of burnout resulting from the conditions of one's work: one should resign oneself to the conditions "as is."

In these modes of intervention directed primarily at the individual, the fault or blame for burnout is placed upon the individual worker. Although these remedies may reduce the expression of burnout, they ignore the core causal sources, and thus are only surface or "tip of the iceberg" solutions. These antidotes:

. . imply that the worker is the major target of change and that if these tactics alone are implemented, worker burn-out will be prevented and better 
services to people will follow. Exclusive reliance on interventions oriented only to the worker may result in a blaming-the-victim attitude--the worker as the victim. (Minahan, 1980, p. 87)

Indeed, since the inability to achieve their objectives and a belief in an inability to control their activities or the work place itself are factors associated with burnedout workers (Minahan, 1980), personal remedies would seem to only alleviate the expression of burnout, while objective conditions of the work place and society, the roots of alienation, would go unchecked.

Christine Maslach states that:

Steps can be taken to reduce the occurrence of burnout because many of its causes are rooted not in the permanent traits of people, but in specific social and situational factors that can be changed. (1976, p. 22)

Therefore, rather than personal remedies which take a blaming-the-victim stance, an objective approach in ascertaining the conditions of the work place and/or societal conditions which are correlated to worker alienation and burnout, is needed to unmask the sources of burnout and effective interventions to prevent its occurrence.

\section{ALIENATION: A SUBJECTIVE EXPERIENCE OR} A SOCIAL-STRUCTURAL CONDITION?

In contemporary social science the concept of alienation can be traced back:

: to the philosophy of history and theory of alienation established by Karl Marx and the theory of anomie developed in twentieth century sociology from Emile Durkheim's work. (Ludz, 1976, p. 31) 
Marx's theory of alienation, which relies heavily on the work of Hegel, is primarily used for empirical studies of work alienation. It was in Karl Marx's writing in 1844, Economic and Philosophical Manuscripts, that the concept of alienation became an empirical-sociological concept rather than merely a philosophical-theoretical concept. Durkheim's theory of anomie and Marx's theory of alienation are frequently seen as interchangeable. For our purposes in this study, alienation will primarily refer to Marx's own definition of work alienation as the "surrender of one's control over one's product and labor" (Schacht, 1971, pp. 91-92). Anomie, a concept frequently confused with alienation, according to J. Horton, focuses on the "relationship between individuals and the constraining forces of social control" and "concentrates on culture or culture transmitted in social organizations" (Ludz, 1976, p. 6).

Marx describes four dimensions or aspects of alienation and these are: (1) from the objects produced, (2) from the work process, (3) from self, and (4) from other men. According to Finifter, the four aspects described by Marx are not "separable and independent dimensions of alienation, but are seen as links in a complex chain of development" (1972, pp. 3-4). For Marx, work was the most important activity for man. He described work as "life activity" because "through work man creates his world and as a consequence he creates himself" (Israel, 1971, p. 37). 
Schacht (1971) gives a detailed description of the dimensions of alienation and examines the classical literature (Marx and Hegel) and modern literature (primarily Horney and Fromm). He concludes that alienation is a "multidimensional" concept and that there is a lack of uniformity in the uses of alienation among sociologists. In regard to work alienation, Schacht states that alienation can mean all or some of the following:

(1) dissatisfaction with one's job,

(2) experience of work as not being intrinsically rewarding,

(3) experience of being insufficiently self-directed, meaningful, and self-expressive. (Ibid., p. 171)

Because alienation can mean many different things to different researchers, Schacht maintains that to operationalize the concept, there must be "objective criteria for the phenomena" (Ibid., p. 200).

The debate concerning whether alienation is primarily a subjective state of individual consciousness or an objective condition of society has persisted in sociologicalempirical literature. Marx, himself, incorporated both "objective" and "subjective" perspectives in his theory of alienation, according to Ludz (1976, p. 29), and Archibald (1976, pp. 64-65). Marx, however, stressed the objective conditions that influenced the worker because Marx always took into account the "historical moment." Man, for Marx, cannot be viewed as separate from the society in which he lives. Schaff explains that the point of departure for 
Marx's theory of alienation was based on Marx's own observations of "market relations in the developing capitalist society" (1970, p. 107). In a Marxian analysis, the economic relationship is basic because the "subjugation and exploitation of man by man" is the source of alienation (Schaff, 1970, pp. 105-123).

Finifter maintains that Marx found it necessary not to merely rely on the subjective, expressed dissatisfactions of workers because:

- . presumably, many have been socialized to expect no more than they actually received; therefore, felt content and did not subjectively experience dissatisfaction or alienation and this he referred to as "false consciousness." (1972, p. 6)

Israel describes false consciousness as occurring when the:

- . alienating processes are either so effective, or have been going on continuously for such a long period, that one no longer experiences them on a cognitive level. (1971, p. 80)

Seeman was among the first to attempt to isolate the aspects of Marx's theory of alienation to allow empirical study. He treated the five variants of alienation--powerlessness, meaninglessness, normlessness, isolation, and self-estrangement--from the "personal standpoint of the actor" and with a "focus chiefly upon the ideas of expectation and value" (1959, p. 784). Thus, alienation was viewed as a subjective or psychological state of the individual. Archibald (1976) attempts to resolve the subjectiveobjective issue by examining more objective behavioral indicators of work alienation. He arrives at four dimensions 
which are similar to Marx's dimensions. They are as follows :

(1) Detachment dimension: "they are indifferent to, not involved with, or detached from the object."

(2) Means-Ends: "to the extent that they approach the object at all they use only a few of its characteristics to achieve only a few, egoistic, narrowly utilitarian ends."

(3) Control-Purposiveness: "the object is not under their conscious control, and they act toward it as if this were the case."

(4) Feelings: "they have certain feelings (e.g., powerlessness or misery) about the object." (Ibid., p. 65)

EMPIRICAL STUDIES ON WORK ALIENATION

The theoretical literature on alienation has dealt primarily with the alienating social conditions and processes. Empirical studies on work alienation have traditionally dealt with individual attitudinal or subjective measures. This is a paradox because the empirical approach allows for describing and defining alienation more objectively, while the theoretical or philosophical approach is usually based on the subjective value judgments of the theorists.

Marx's analysis of alienated labor holds that particular aspects of factory work necessarily lead to feelings of alienation in a capitalist system of economic organization. Marx did not concern himself with how the kind and extent of alienation may vary as a result of differences among factory organizations or types of industry. However, industrial production under capitalism has evolved in a number 
of ways and industrial production differs in many structural features.

Blauner (1964) attempts to analyze how different patterns of industrial organization affect alienation from work. Blauner, in Alienation and Freedom, focuses on the nature of the work process. He was concerned with the various levels of technology in industries. Blauner used a lengthy questionnaire to collect data from three thousand blue-collar workers in sixteen different factory industries. Alienation for Blauner consists of a "general syndrome" consisting of both subjective feeling and objective conditions. His definition of work alienation is as follows:

Alienation exists when workers are unable to control their immediate work processes, to develop a sense of purpose and function which connects their jobs to the overall organization of production, to belong to integrated industrial communities, and when they fail to become involved in the activity or work as a mode of personal self-expression. (Ibid., p. 15)

Blauner's work is a vital contribution to the study of work alienation because he did not concern himself merely with the psychological adjustment of the worker, but also made an effort to examine structural causes of alienation so that solutions to alienation could be undertaken. However, a shortcoming of Blauner's work is that he failed to incorporate Marx's idea of the "ownership of production" and contends, with Weber, that "bureaucracy rather than capitalism is the more general cause of alienation from work" (Archibald, 1976, p. 69). 
What was Marx's view of bureaucracy? Hasenfield and English summarize the Marxist conception of bureaucracy as:

- . the state itself through which the dominant social class exercises its power and domination over other social classes. Therefore, bureaucracy for Marx is only one instance of the general process of alienation. (1974, p. 25)

Work alienation can also be affected by certain personal characteristics of workers. Because the personal characteristics may interact with the actual working conditions and consequently influence the relationship between working conditions and alienation, studies of work alienation cannot ignore the possible influence of individual personal characteristics.

Leonard Pearlin (1962) examines how authority relationships and other structural conditions of a large federal mental hospital are related to alienation from work. However, he specifically examines how personal characteristics affect workers' feelings about their work. According to Finifter, Pearlin demonstrates:

- . clearly that psychological characteristics and aspirations of individuals must be taken into account in assessing the degree to which specific work conditions are alienating. (1972, p. 105)

Miller (1972), in his study of scientists and engineers of a major aerospace company concerned himself primarily with how professional socialization experiences and professional values affect reactions to work environments. He was not as concerned about power and control over work tasks and the work situation as was Pearlin (1962), but 
rather emphasized the degree of ego and personal involvement that the worker has over his work. He concludes that those workers who choose extrinsic incentives over intrinsic incentives may be considered alienated from their work.

But individual personal characteristics are not the only variables which explain the relationship between the work situation and alienation from work. Values and norms may also be variables that influence the relationship. Zurcher, Meadow, and Zurcher (1972) did a cross-cultural study of value orientations, role conflicts, and alienation. This study involved Mexican and American banks because it provided the researchers with accessible as well as comparable bureaucratic organizations from which to draw subjects Their findings concluded that cultural groups and values influence individual reactions to the work situation.

The context of the studies of Pearlin (hospital), Miller (aerospace manufacturing), and Zurcher et al. (bank) are essential conditions and structures found in all bureaucratic organizations. Hence, it leads to the question of whether bureaucracy in and of itself leads to work alienation. In recent decades, the increase of the bureaucratization of organizations and the simultaneous increase in the professionalization of work have resulted in numerous studies concerning the nature of professional-bureaucratic relationships. Even though our study will not focus on the issue of 
whether bureaucracy in and of itself causes alienation, we do find that we cannot ignore this area.

Three basic structural elements that have been identified as "intrinsically problem generating" are "hierarchy of authority, specialization of tasks, and functions and rules and regulations" (Braeger \& Halloway, 1978, p. 8). Hall (1968) identified similar dimensions which, in a continuum, are characteristic of a "bureaucracy." Aiken and Haage (1966), Blauner (1964), Bonjean and Grimes (1970), and Neal and Rettig (1963) are only a few of many empirical studies dealing with the relationship between bureaucratization and alienation.

Murdia (1979) in her study of precarious and predictable human service organizations in India concludes that more respondents from predictable organizations (those displaying bureaucratic structures) are more alienated than respondents from precarious organizations (non-bureaucratic). She concludes that there is a "significant association between the degree of work alienation and the perception of the decision-making structure" (Ibid., p. 174).

And, in addition to the vast amount of literature dealing with bureaucratization and alienation, there is also a vast amount of literature concerning the conflict between professional self-direction and bureaucracy (Finch, 1976; Ha11, 1968; Billingsley, 1974; Wasserman, 1971; Green, 1966; Pruger, 1973). A study by Morrisey and Gillispie from the 
University of Washington suggests that the relationship between:

- . professionalism and bureaucracy is not simple and direct as presumed in much of the literature, but rather that the technology of an organization greatly affects the kinds of rules and procedures that may affect professional autonomy. (1973, p. 330)

How the growth of industrialization has affected work and workers' feelings of work was studied by Braverman (1974). In his work Labor and Monopoly Capital, he shows how technology and science successfully bring the process of production under the control of management, and how capitalist management has encouraged division and subdivision of labor. He uses a Marxian analysis to show how the division of labor leads to workers' loss of control over the product and process of labor, as well as how the separation of mental and manual labor occurs.

Thomson, in a study conducted at the University of Michigan, attempted to examine whether "it is possible to operationally define some of the theoretical concerns of Marx and Braverman," and to examine the differences and similarities between clerical workers and other occupational categories (1979, p. 7). Using survey data based on a national random sample of 1,496 workers, she attempted to examine the nature of work rather than the subjective or psychological experiences of workers. Respondents were requested to respond to the objective conditions of their work in regard to "extent of control, creative and 
spontaneous activity, use of mental processes and job activities which are highly rationalized" (Ibid., p. 6). The study confirmed Thomson's hypothesis that the nature of clerical work involves activities that are more similar to the factory worker than that of a "new thriving middle class" (Op. cit.).

Naik (1978) was also interested in "white-collar workers." In her study of 101 employees of the banking industry in India, her findings are as follows:

The data obtained show that there was hardly any relationship between the alienation scores and such bio-data variables as the length of service in the bank, years spent in the present department, or the years of prior experience. Age of the employees bears a negative relationship to work alienation only; with the exception of the factor pertaining to job satisfaction from pay, all other job satisfaction shows a negative relationship to work alienation. (Ibid., p. 247)

Tudor replicated previous empirical research in the area of job complexity and feelings of powerlessness. His study involved a "nationally representative sample of native-born, non-agriculturally employed white males," interviewed in 1960 and 1964 (1972, p. 597). Tudor's findings were that lack of occupational complexity is related to feelings of powerlessness for a minority of the work force; the relationship is weaker for lower income occupational categories. He contends that variables such as "education or income rather than job complexity may really explain the extent to which lower income men feel alienated" (Ibid., p. 602). 
In contrast to researchers who maintain that technological conditions are a source of work alienation, Goldthorpe (1966) concludes that social conditions determine workers' feelings of alienation. His study of workers at the Vauxhall car factory in Luton, England was comprised of respondents who all worked on the conveyor belt and who all expressed dissatisfaction with their work. He maintained that all the workers had a "purely instrumental attitude" toward their work because they did the work merely to satisfy needs outside of work (Ibid., p. 119). Goldthorpe concluded that the workers were alienated even before they sought the job; therefore, the roots of alienation must be sought:

. . in those aspects of the wider society which generate their tremendous drive for economic advancement and disregard for the costs of this through the impoverishment of their working lives. (Ibid., p. 119)

Neal and Seeman (1964) examine the relationship between organizational membership and powerlessness. They found that there is a weak relationship between powerlessness and organizational membership for individuals who have experienced "upward mobility" or success. They also found that the white-collar workers perceived a worker association as an instrument of social personal mobility; the manual worker perceived it as a source of group and economic security. Hence, it appears that, in a capitalist system, the drive for status and/or achievement may dull an awareness or consciousness of alienation from one's work. 
Kohn (1976), however, hypothesizes that neither the explicit or implicit consequences of capitalism nor bureaucracy are the primary sources of alienation in this industrial society. His study is particularly interesting for our own research because he attempts to link the socialstructural and psychological factors in his study of U.S. males employed in civilian occupations. He maintains that occupational self-direction is of major importance to workers, but that occupational self-direction may be sacrificed by workers in favor of job security in a time of economic uncertainty; the conditions of society or the "historical moment" cannot be ignored. Kohn utilizes a Marxist paradigm and concludes the following:

In this large-scale capitalist economy, the type of control that is most important for alienation, though, is control, not over the product, but over the process, of one's work. Ownership, hierarchical positions, and division of labor have less effect on workers' feelings of alienation than do closeness of supervision, routinization, and substantitive complexity. (Ibid., pp. 126-127).

Kohn also argues that positive and negative experiences are carried over into other non-occupational realms. He disagrees with Melvin Seeman's conclusion in this regard. Seeman (1967) studied work alienation in respect to the potential personal consequences that may result if work is not intrinsically satisfying. His study centered around a sample of males in commercial and seafood occupations in Malmo, Sweden. Seeman's findings were that alienation experienced at work did not have serious social consequences 
and is not generalized into other areas of social life. Seeman did not attempt to explore Marx's theory that alienation from work is tantamount to alienation from self and from humanity (Finifter, 1972).

In our review of the literature concerning work alienation we have not found a study focusing on social service workers that attempts to bring the structural and psychological factors together as Kohn so successfully managed to do in his study. We do know that the structure or form of social service organization is not the only variable which may be the source of structural alienation for social service workers. Brager and Halloway (1978) and Galper (1975) maintain that the conflicts in the larger society also have an impact on social workers and organizations. They maintain that the social service field is greatly affected by conflicting ideologies and values. Even though our country supports social service programs, there still exists a great deal of ambivalence in society concerning the spending of tax monies for social service programs. Social service workers not only have to deal with societal ambivalence about providing social servcies, but they also have to deal with the contradictions in the mandates given them by social service organizations. Social workers are not only called upon to provide services to the needy, but are also implicitly mandated to function as "social control agents" for the larger society--to keep certain members of 
society in line. Social service workers also are beset with problems stemming from the conflicting ideologies within the social work profession itself; therefore, after being socialized into the profession, they learn that not all members of the profession share the same values about the role of social service work in our society.

\section{OBJECTIVE OF STUDY}

In this study, we are primarily interested in examining how the structure of the work place and societal factors contribute to the subjective experience of alienation. More specifically, we want to explore the relationship between the objective conditions of the work place and the subjective experiences of alienation. Secondly, in keeping with a Marxist paradigm, we want to focus on the socialstructural conditions and examine whether economicsociological processes (societal factors) rather than the organization of the work itself leads to feelings of alienation and dissatisfaction with work for social service workers .

Geyer and Schweitzer state that:

While the distinction between subjective and objective alienation is often drawn in theory (Schacht, Archibald, Ludz), one of the challenging tasks which remains is to specify conceptually, and demonstrate empirically, the exact nature of the linkage between them. (1976, p. xxiii)

This stated challenge is the focus of our study. It is our hope to begin to formulate the distinction between 
subjective and objective alienation and the connection between them, and to identify variables which may influence or impede the subjective expression of alienation.

In line with the above objectives, we propose the following hypotheses :

Hypothesis 非: We will find more structural and societal alienation than subjective alienation.

Hypothesis 非: There will be an association between structural/societal alienation and subjective alienation.

Hypothesis 非: The social "reality" variables are likely to influence the relationship between the structural and societal variables and our measures of subjective alienation. 
CHAPTER II

\section{METHODOLOGY}

Survey methods were selected to investigate the relationship between the objective working conditions of social service workers and their subjective expression of burnout and alienation. Through these methods, we were interested in the relative influence of the structure of the work place, societal conditions, and social reality on the subjective experience of alienation. To this end, we selected a sample and developed a questionnaire for mailing.

\section{THE VARIABLES EXAMINED}

Because of time constraints, limited funds, and a desire for a large sample, it was decided that a mailed questionnaire should be developed. Such a questionnaire has limitations. One has to be concerned with length. One must ask questions that are easily answered, and thus it is difficult to include content that goes beyond a superficial analysis of the research issues. One is always concerned with the fact that the return rate will not be as good as with some more face-to-face approaches. These considerations were weighed against our goals, and the decision to develop a concise but meaningful questionaire was made. 
Because of the novelty of our theoretical orientation, there were no previously developed instruments available to test our hypotheses. It therefore became necessary to develop such an instrument. The statements in the questionnaire were derived from a variety of sources, but are primarily a result of our ideas and attitudes about alienation and work (Maslach, 1976; Archibald, 1976; Schacht, 1971; Ha11, 1968; Braverman, 1974). The first section of the questionnaire asked for general personal information. The second section listed a series of statements about the structural aspects of work, including statements regarding societal and social reality factors which influence work. The third section concerned the respondents' subjective experience of burnout. The questionnaire also contained a cover letter and a space for comments.

This study, however, did not focus on all the variables operationalized in the questionnaire. Four types of variables were analyzed: structural, societal, social reality, and subjective, using several statements from each type of variable. The examples given are the statements upon which we did our analyses as these variables were highly indicative of alienation after the initial coding of the data.

The first set of variables with which we are concerned are those that deal with structural aspects of the work situation. These included measures of bureaucracy and measures 
of societal alienation, both of which have been examined by other researchers (Sherman \& Wenecour, 1980; Muldoon, 1980; Archibald, 1976). The concept of structural alienation is an attempt to measure the objective work conditions of social service workers. Following Braverman (1974), Archibald (1976), and others, we attempted to measure at the structural level such concepts as powerlessness, meaninglessness, social isolation, and alienation from production, from other workers, and from the self. To do this, we asked the respondents to answer statements such as the following: "unclear expectations," "access to administration," "learn new things." Respondents were given a series of eighteen such statements to which they responded on a 6-point Likerttype scale. The range was from "very descriptive". to "very "non-descriptive." This technique, while not completely free of subjective bias, is similar to techniques used by Thomson (1979) in testing Braverman (1974). (This is possibly the only way that structural variables are measurable when utilizing survey techniques.) These measures are at the heart of the study and will serve as the independent variables. It is our belief that subjective alienation will not be admitted unless alienation at the structural level is evident. Because we also believed that social workers could experience burnout as a function of the pressures of being a welfare organization in a capitalist society, we have included nine statements measuring such things 
as the choice workers had over clients, severity of the economic problems their clients were faced with, the stability of funding resources, and the resources and support available in the community. These variables are referred to as societal alienations and are treated as independent variables.

In addition, respondents were asked to evaluate the social reality factors (variables) of their work, such as their pay and position with regard to existing market conditions and the opportunities for advancement. These statements were also measured on a 6-point Likert-type scale from very descriptive to very non-descriptive. The social reality variables are treated here as an intervening variable since they are likely to influence the relationship between our structural and societal variables and our measures of subjective alienation.

Because the questionnaire was being sent to private practitioners who, by definition, do not work in bureaucracies and agencies, a "not applicable" category was included in our scale of possible responses. Our findings did indeed suggest that private practitioners mostly used this response.

The final set of variables dealt with the subjective experience of burnout and alienation. Respondents were asked such statements as the following: "My job is strictly a means to an economic end"; "Too many people dictate how my 
work is to be carried out"; "I get tired of listening to other people's problems"; "If I had to do it over, I would choose this job/career over again." On a 6-point Likerttype scale, ranging from "completely agree" (CA) to "completely disagree" (CD), workers responded to twenty-six attitude statements. These statements, in keeping with the Marxist perspective, especially relied on the suggestions of Archibald (1976). Thus, our statements tried to measure detachment, controlled purposiveness, means/ends, and feeling. The responses were coded according to the degree of alienation, a score of " 1 " being a non-alienated response.

\section{STATISTICAL ANALYSIS}

In doing the analysis of the relationship between the four types of variables, we used gamma. We were testing for the strength of association between the structural, societal, and subjective variables. These are zero-order correlations. Further, we examined whether these associations became weaker or stronger when controlled for by the social reality variables. These became the second-order correlations.

\section{GAMMA}

The statistic which will be used for the results of our research is the gamma coefficient. Comparing the rank orders of variables for each respondent on one scale (e.g., 
structural alienation), we are attempting to predict the rank order of variables for each respondent on another scale (e.g., subjective alienation).

Gamma measures the strength of association between pairs of variables ranked on an ordinal scale. Therefore, gamma may be interpreted as a measure of proportional reduction in error. For example, we have predicted that a social service worker who ranks high on our measures of structural alienation will also rank high on our measures of subjective alienation. Gamma measures the likelihood of error in this prediction. A gamma of .75 , for instance, tells us that ranks of pairs of variables will consistently be in predicted order in 75 percent of the cases and inconsistent in 25 percent of the cases. A negative gamma tells us that the predicted order of ranked pairs is reversed. Using the same example, with a negative association we would find 75 percent of the cases having high structural alienation to also have a low rank on the subjective scale.

Gamma thus shows consistency in rank. The proportionally consistent responses can be in the predicted rank $\operatorname{order}(\mathrm{A}=$ High, $\mathrm{B}=$ Low $)$, or can be consistent in the reverse order $(B=$ High, $A=$ Low $)$.

Tests of significance will not be used in this study. Instead, we will rely on simply describing the gamma according to the degree of association evident in the result. In general, we have arbitrarily selected .25 as a point below 
or above which relationships may be described as weak or strong. Gammas below .25 will be described as indicative of little or weak association. Gammas at or around .25 will be seen as showing moderately strong association. Gammas well above .25 will be referred to as indicative of a strong relationship.

\section{SENT SAMPLE}

Our sample was obtained through a variety of means. The private practitioners were culled from the pages of the Registry of Clinical Social Workers of the State of Oregon. We also asked people for names of those social workers they knew in private practice, and we sent fiftyfive questionnaires to this group. We contacted the Oregon Chapter of the National Association of Social Workers for their current mailing list, and from this list we eliminated faculty from Portland State University, retired workers, students, and those not residing in the Willamette Valley or the Portland metropolitan area. Questionnaires were mailed to 699 people on this list.

We were also able to obtain the names of all those people currently employed at the metropolitan offices of Adult and Family Services and the Children's Services Division. From these lists, we eliminated all those who were not in some significant way involved with clients, and thus 509 questionnaires were then hand-delivered or mailed. We 
also hand-delivered or mailed 181 questionnaires to social service workers in a variety of agencies throughout the metropolitan area. We also gathered as an accidental sample the names of forty-five social service workers who have advanced degrees but who are not members of the National Association of Social Workers (NASW), and these people also received questionnaires.

Thus, a total of 1,489 questionnaires was handdelivered or mailed out.

\section{RETURNED SAMPLE}

The overall return rate on our sample was a very acceptable 38.5 percent. Of the 1,489 questionnaires sent out, 573 were returned. Of these, 30 could not be used largely because the respondents were either retired or unemployed. An additional 60 came in after the cutoff date. The final number was 483 .

Due to the fact that we asked that a worker's place of employment be kept confidential, it was impossible to determine from which specific segment of our sent sample our returned sample was derived. Two hundred sixty-three of the respondents had master's degrees or higher. One hundred thirty-two had bachelor's degrees or had done some graduate work. The other eighty-eight respondents fell below this educational level. One hundred thirty-five respondents were male, 305 female; forty-three chose not to respond. 
Although we derived some 699 names from NASW's lists, only 181 people stated that they were members of NASW. Some sixty-three, eight more than we expected, of our respondents stated that they were in private practice; however, of these, only eighteen were solely private practitioners (see Figure 1).

One hundred forty-nine of the respondents were caseworkers, while one hundred stated that they were social workers or clinical social workers. Fifty-six were counselors, while eighty-nine people were in administrative or supervisory positions (see Table I). For 276 of the respondents, their chief duties involved casework. One hundred forty-five of the respondents' duties were supervisory, administrative, as advocates, community organizers, and teaching, or combinations thereof (see Table II). Four hundred twenty-seven of the respondents worked in agencies, 317 in public agencies and 110 in private agencies (see Table III). Because we were assuming that social workers in agencies will experience much the same sort of alienation as factory workers (Braverman, 1972), it was essential for our study to have a large portion of the returned sample work in agencies, and especially in public agencies. It is difficult to make strong comparisons between the sent and the returned samples. Too little specific data were available about the sent sample, save some data that we did not use, e.g., place of employment. We did not keep a record of the 


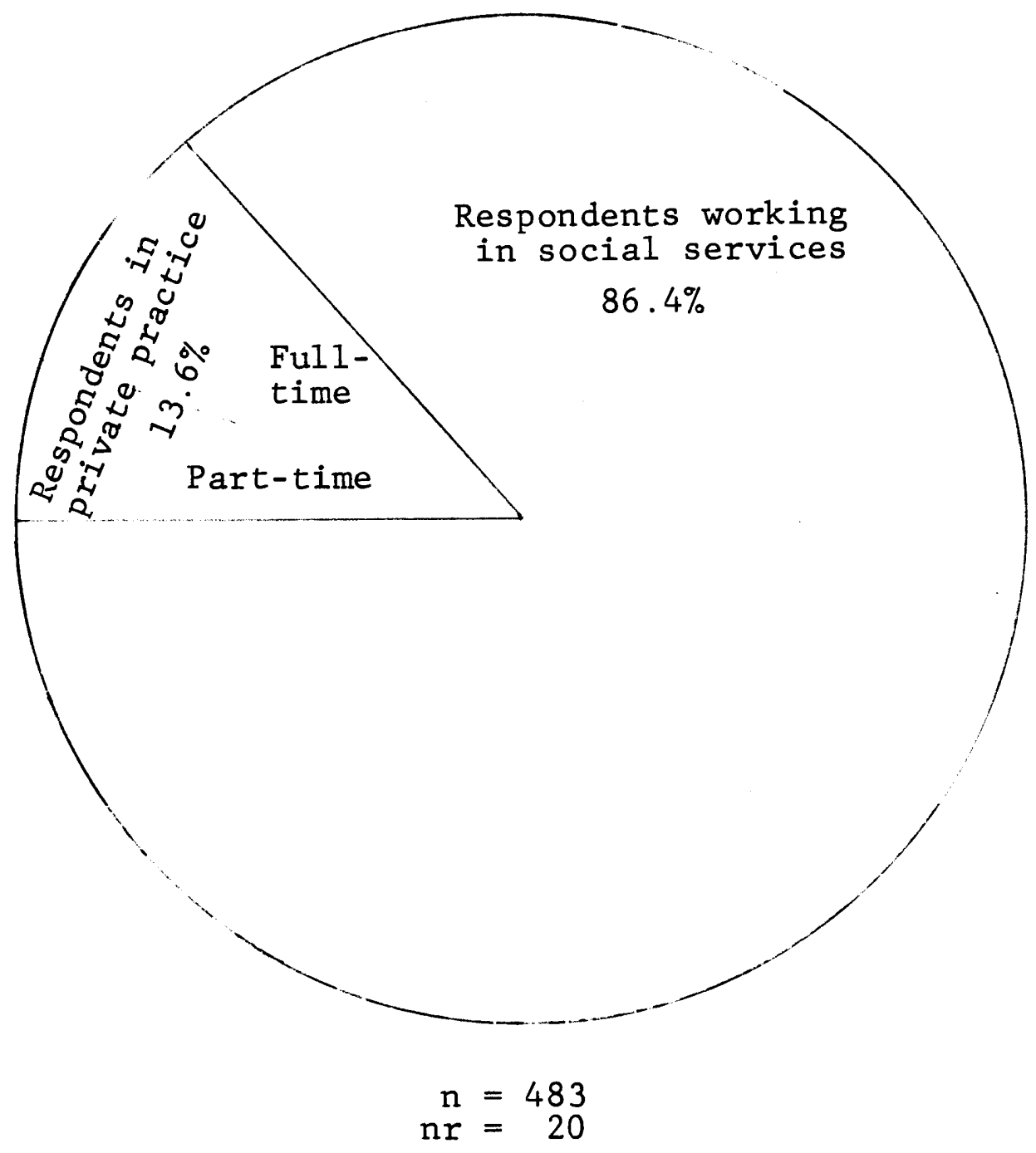

Figure 1. Respondents in private and public practice. 
TABLE I

JOB TITLES OF SOCIAL SERVICE RESPONDENTS

\begin{tabular}{lcc}
\hline \multicolumn{1}{c}{ Job Title } & $\begin{array}{c}\text { Number of } \\
\text { Respondents }\end{array}$ & Percent \\
\hline Caseworker & 149 & 30.8 \\
Social Worker/Clinical Social Worker & 100 & 20.7 \\
$\begin{array}{l}\text { Counselor/Probations Juvenile } \\
\text { Counselor }\end{array}$ & 56 & 11.6 \\
$\begin{array}{l}\text { Administration/Director Program } \\
\text { Manager }\end{array}$ & 64 & 13.3 \\
Supervisor & 25 & 5.2 \\
Other & 25 & 5.2 \\
NA/NR & 64 & 13.2 \\
$\quad$ Totals & 483 & 100.0 \\
\hline
\end{tabular}

TABLE II

CHIEF DUTIES OF SOCIAL SERVICE RESPONDENTS

\begin{tabular}{|c|c|c|}
\hline Duty & $\mathrm{N}$ & $\begin{array}{l}\text { Adjusted } \\
\text { Frequency, } \\
\text { in Percent }\end{array}$ \\
\hline $\begin{array}{l}\text { Caseworker/Counselor; Medical } \\
\text { Eligibility; Outreach }\end{array}$ & 276 & 33.8 \\
\hline Supervision & 29 & 13.0 \\
\hline $\begin{array}{l}\text { Administration; Bookkeeper; } \\
\text { Program Evaluator }\end{array}$ & 36 & 9.9 \\
\hline $\begin{array}{l}\text { Other; Liaison; Community Organiza- } \\
\text { tion; Advocacy, Teaching }\end{array}$ & 18 & 8.0 \\
\hline $\begin{array}{l}\text { Mixed (Combination of Casework } \\
\text { and Supervision) }\end{array}$ & 56 & 33.5 \\
\hline Consultation & 6 & 1.8 \\
\hline
\end{tabular}


TABLE III

TYPE OF AGENCY

\begin{tabular}{ccc}
\hline Type of Agency & $\begin{array}{c}\text { Number of } \\
\text { Respondents }\end{array}$ & Percent \\
\hline Private Agency & 110 & 22.8 \\
Public Agency & 317 & 65.6 \\
NA/NR & $\underline{56}$ & $\underline{11.6}$ \\
Totals & $\underline{\mathrm{n}}=483$ & 100.0 \\
\hline
\end{tabular}

sex of the recipients of the questionnaire, nor did we always know their level of education. Forty-seven percent of our sent sample were members of NASW, while 37.5 percent of the returned sample were. No comparison can be made on the basis of age or number of years the sample worked in social services, as we did not have this information on the sent sample.

While we attempted to address a large number of people, we do have a biased sample in that a large percentage of our respondents were selected on the basis of their working for public agencies. In trying to generalize our results to the whole population which received questionnaires, as well as to all social service workers, we believe that our results do to a certain extent apply.

We have a large $\mathrm{N}^{\prime}$; respondents were derived from at least two major public agencies. There are a large number of NASW members, a large percentage of MSWs (see Figure 2) and about the same ratio of male to female workers is in 
the $\underline{n}$ as for the general population of social service workers in Oregon (63.1 percent women to 36.9 percent men) (see Figure 3). However, with the exception of this division between the sexes, there is no other way to see if systematic bias is evident within the study. Furthermore, because our study was limited to social service workers within Oregon and contained an accidental sample of non-NASW MSWs, we can conclude only that our results might be applicable to social service workers in Oregon, especially in the Portland metropolitan area. We cannot assume that the results are generalizable to all social service workers. Our findings will be useful for discussion and as a basis for further study.

\section{LIMITATIONS OF THE STUDY}

There are a number of limitations within this study. Not all the issues pertaining to burnout were studied. We acknowledge that other variables are important, such as educational background, place of work, union affiliation, and personality. Further, we did not examine ways in which workers' handling of burnout helps to combat it. These important issues are beyond the scope of this study.

A second major limitation has already been noted. The results presented here are at best applicable to social service workers in the Portland metropolitan area. Although they might apply to all social service workers, we cannot 


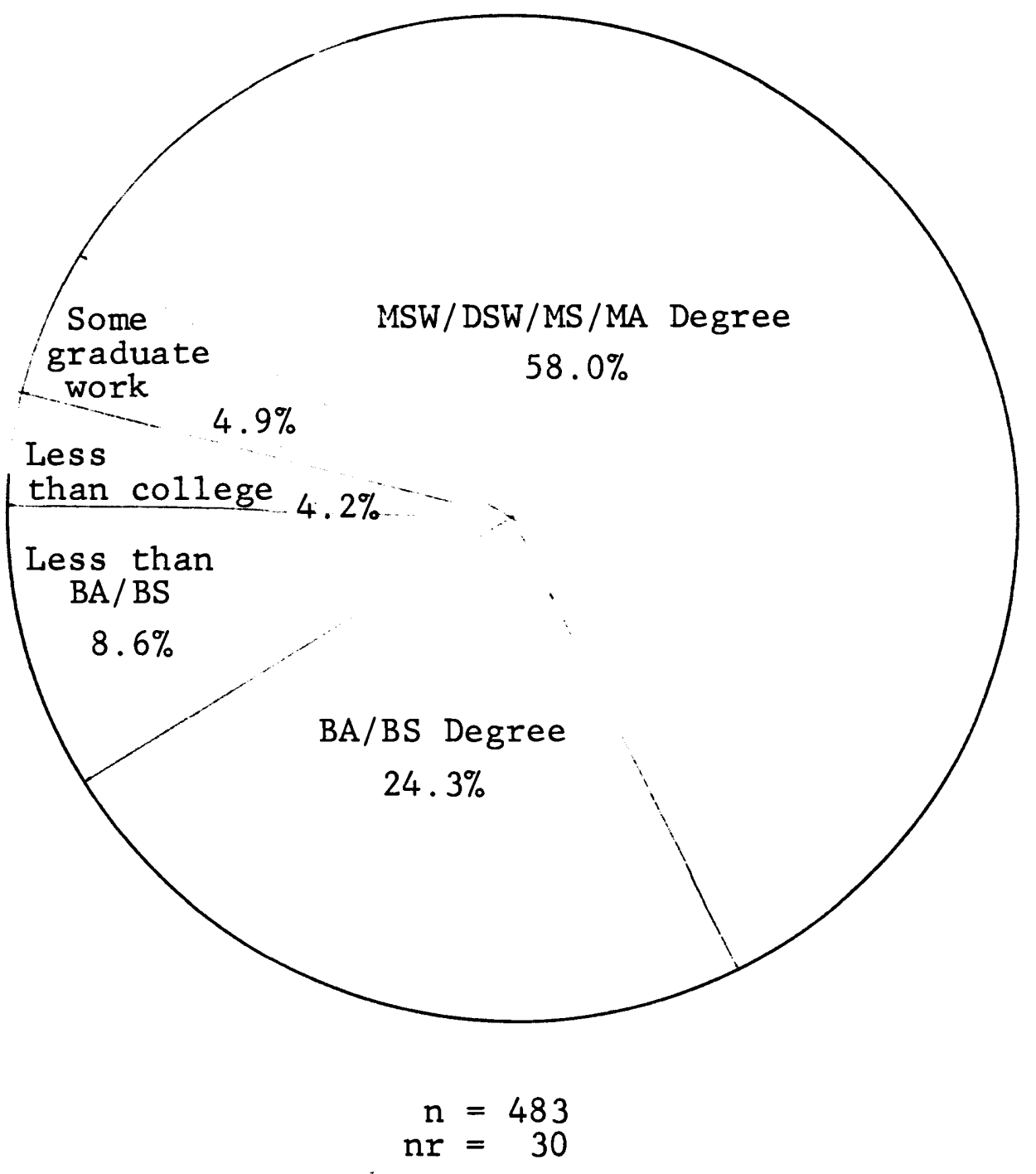

Figure 2. Education of respondents. 


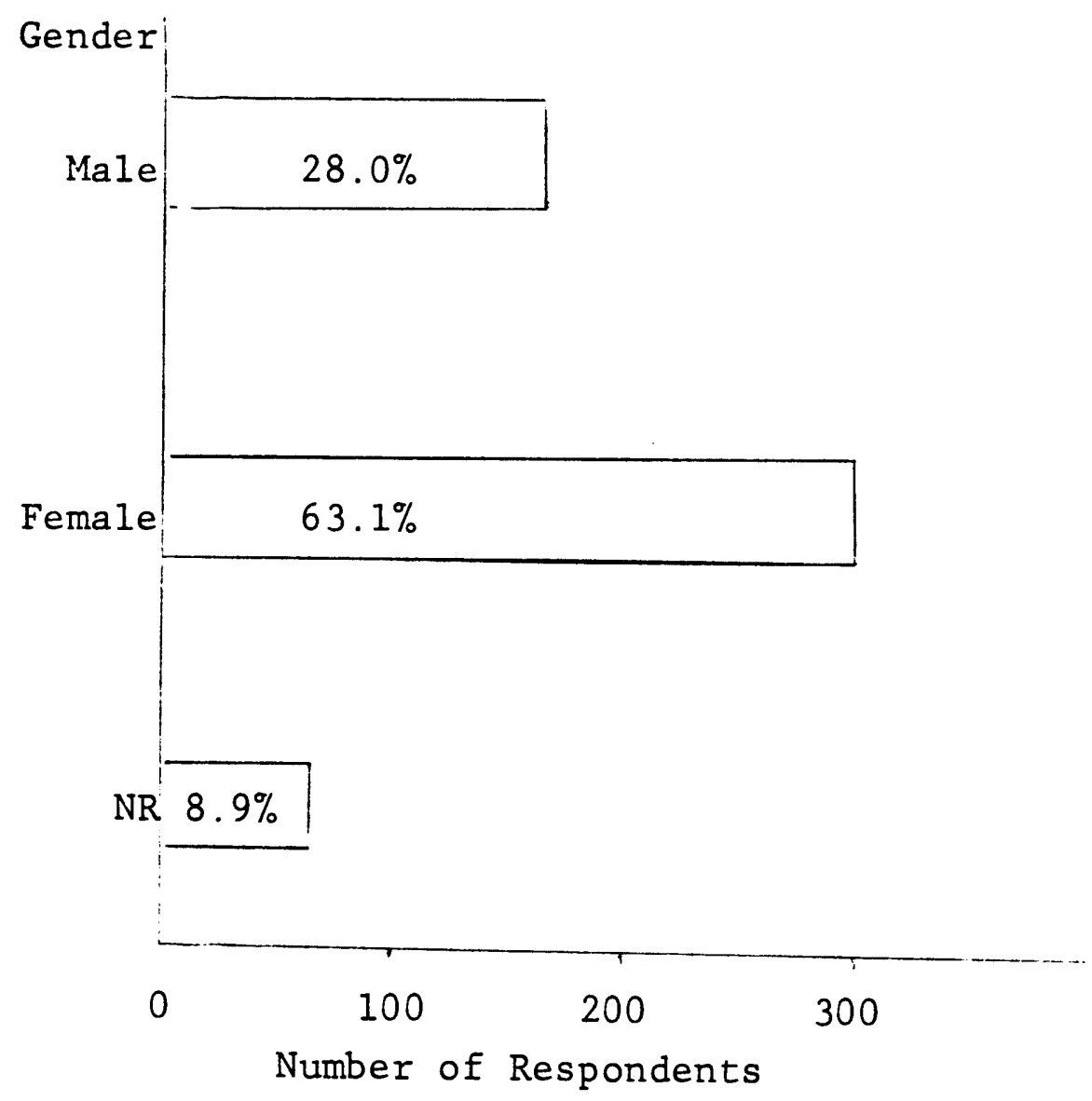

Figure 3. Gender of respondents. 
assume their applicability. The results are presented because of their inherent value to the study of burnout and to serve as a basis for further research.

\section{ETHICAL ISSUES}

When designing and implementing our survey, there were several ethical issues to be taken into consideration.

To insure confidentiality for our respondents, we used address labels on the questionnaires which could be removed prior to their return. We advised the respondents of this in a letter which was included in our questionnaire. Further, this letter informed the respondents, to some extent, of the nature of our study. While we did not state that our study intended to examine burnout/alienation from a Marxist perspective, we did say that we were looking at the way a social worker's job was organized and his/her attitudes toward the job.

In hand-delivering our questionnaires to certain agencies, some members of our group encountered difficulties. Various supervisors were suspicious, wanting to know very specifically what our study was about and why we were engaged in such an endeavor. In trying to understand the negativity of some of the supervisors and agencies, we hypothesized several things. Anti-intellectualism is deeprooted in our society, regardless of level of education. This often manifests itself in mistrust of new information. 
Too, there may have been a fear that this questionnaire was merely a front for gathering information for subversive use. This occurred despite the fact that we had prepared and delivered letters of introduction prior to the completion of the questionnaire. However, these people were in the minority. Most of the recipients of the questionnaire were extremely open and interested in our study. 
CHAPTER III

\section{DESCRIPTION OF THE VARIABLES}

\section{INTRODUCTION}

The focus of our study is alienation: structural/ societal alienation and subjective alienation. We specifically attempt to examine how the structure of the work place and societal factors contribute to the subjective expression of alienation, and whether there is any association between objective and subjective work alienation.

In this chapter we will discuss how we operationalized our independent variables (structural and societal alienation), our dependent variable (subjective alienation), and our intervening variable (social reality). We will then describe our findings in regard to the responses to the specific variables selected and discuss what these findings may mean regarding work in the social services.

\section{STRUCTURAL ALIENATION}

As noted in the methodology chapter, respondents were requested to respond to phrases that describe the conditions under which they currently are working. The eighteen items used were designed to tap objective work conditions that frequently exist for social service workers. We refer to 
these items in our study as structural alienation variables.

In keeping with a Marxist paradigm, we attempted to include items which correspond to alienation from self, alienation from product, and alienation from others. We also incorporated items which correspond to Archibald's dimension of "detachment, means-ends, control-purposiveness, and feelings" (1976, p. 65). Dimensions of meaninglessness and powerlessness were also included (Seeman, 1959). The phrases consist of simple words such as "paper work," "flexible procedures," "participation in policy," "requires high skill," and "routine work," so as to allow the respondent to assess his/her working conditions as objectively as possible.

Studies such as Hackman and Lawler (1971) have provided evidence that the worker's assessment of the job closely parallels the opinion of the outside observers. (Thoms on, 1949, p. 6)

Because this section of our questionnaire was so packed and so rich with information, the analysis here will concentrate on three basic items that we believe are central to the concepts of alienation from work. Since Marx's own description of non-alienated work focuses on elements such as "creative activity," "control," and "relatedness to self and others," we chose three variables in our study that typify these concepts. And, because Marx viewed work as "life activity" in which "man creates his world and as a consequence creates himself" (Israel, 1971, p. 80), we were 
interested in exploring whether the conditions of work for social services were conducive to self-growth.

The first variable we chose, "learn new things," refers to conditions of the job which allow social service workers to be creative, to be in tune with their "species nature," and to be enriched by their work. When a person has little opportunity to learn new things on the job, s/he is objectively alienated because, according to Marx, "personal development is limited and minds are stunted" (Archibald, 1976, p. 64). Empirical studies (Kohn, 1976; Thomson, 1979 ; Pearlin, 1962, for example) demonstrate that selfdirection and creativity are very important components of rewarding and non-alienated work.

Being able to have influence over the actual work process and to have input into decision making are also important characteristics of non-alienated work. The second variable, "access to administration," refers to having some control or power over the process and product of one's work. Empirical studies of work alienation (Blauner, 1964; Thomson, 1979; Pearlin, 1962; Murdia, 1979) clearly demonstrate the importance of workers having access to decision making.

The third variable, "unclear expectations from others," refers to the dimension of alienation from others. Social service workers are frequently called upon to carry out conflicting directives because they are caught between serving the needs of clients and serving the interests of 
the employing agency. Because the human service field is beset with an array of conflicting ideologies, individual social service workers are constantly faced with having to reconcile contradictory or unclear expectations from members of the profession, from human service organizations themselves, and from the sentiments of American society. Dealing with such stress can easily lead to feelings of alienation from others and from one's work.

Table IV shows the frequency distributions for the three variables chosen. The table is arranged in descending order from the highest to the least alienating conditions.

TABLE IV

STRUCTURAL ALIENATION: FREQUENCY OF RESPONSES IN PERCENT ${ }^{a}$

\begin{tabular}{|c|c|c|c|c|c|}
\hline Variables ${ }^{\mathrm{b}}$ & $\begin{array}{c}\text { Percent } \\
\text { High } \\
\text { Aliena- } \\
\text { tion } \\
\end{array}$ & $\begin{array}{c}\text { Percent } \\
\text { Moderat } \\
\text { Aliena- } \\
\text { tion } \\
\end{array}$ & $\begin{array}{l}\text { Percent } \\
\text { e Low } \\
\text { Aliena- } \\
\text { tion } \\
\end{array}$ & $\begin{array}{c}\text { Total } \\
\text { Percent }\end{array}$ & $\mathrm{n}$ \\
\hline $\begin{array}{l}\text { Unclear expectations from } \\
\text { others }\end{array}$ & 26.1 & 42.6 & 31.3 & 100 & 472 \\
\hline Lack of access to administration & 21.6 & 36.3 & 42.2 & 100 & 441 \\
\hline $\begin{array}{l}\text { Lack of opportunity to learn } \\
\text { new things }\end{array}$ & 17.0 & 42.8 & 40.0 & 100 & 482 \\
\hline
\end{tabular}

aHigh alienation means a response of very descriptive and somewhat descriptive; moderate alienation means a response of somewhat descriptive and somewhat not-descriptive; low alienation means a response of not-descriptive or very not-descriptive,

${ }^{b}$ Some items were reworded to facilitate presentation. Refer to questionnaire in the Appendix for the original wording of items. 
The response to the phrases forms a consistent pattern. Most respondents indicated moderate to low structural alienation. "Unclear expectations" showed the highest amount of structural alienation; 26.1 percent of the respondents agreed with the statement. Slightly over 21.6 percent agreed that they had a lack of "access to administration." Finally, only 17 percent agreed that they lack opportunity to "learn new things" on the job.

In sum, in this section we looked at alienation as a function of the conditions under which social service workers operate. The three variables we concentrated on represented major concepts of objective work alienation as set forth by Marxist thought.

Interestingly, the respondents acknowledged that the three variables we chose to analyze play a part in how they view their work, but social service work conditions are less structurally alienating than we predicted. For instance, creativity on the job appears to be fairly characteristic of work in the social services. On the other hand, being involved in the decision-making process and having a clear indication of what is expected of them by others appears to be somewhat more conducive to structural alienation in our sample. Respectively, this is indicative of a degree of powerlessness and alienation from others. However, the majority of respondents agreed that these were conditions only somewhat descriptive of their jobs. 
Why is it that these structural conditions, which previous studies have postulated to be conducive to work alienation, did not appear to be as characteristic for the respondents in our study? One explanation may be that work in the social services is basically unlike work previously studied, and that work for social services allows for more freedom, creativity, and involvement in the lives of others than does work in more highly technological and routinized division of labor fields such as factory labor or clerical work. Social service workers may derive more intrinsic satisfactions from their work as a result of their educational level and, consequently, may not be bothered by structural impediments on their jobs. Or conversely, due to their educational level and the complexity and scope possible in social service work, they may be given more autonomy than the working class. Perhaps in a semi-profession such as social service work, education and income level may be of more importance than other objective conditions of the work place (Tudor, 1972).

Another explanation may be that it is a function of the three variables analyzed. These three are reflective of an important but small part of the total work experience. For instance, we did not look at other variables like paper work, amount of routine, or the flexibility of procedures. It may be that had other structural variables been analyzed more structural alienation would have been reported. 
SOCIETAL ALIENATION (INDEPENDENT

VARIABLE)

Along with work conditions, conditions in the society may result in alienating circumstances. Man, according to Marx, cannot be viewed as separate from the society in which he lives; rather, he views the relationship between man and society as a reciprocal one. Man forms society and is in turn formed by society. Society, in a Marxist definition, "does not consist of individuals, it expresses the sum of connections and relationships in which individuals find themselves" (Anderson \&Gibson, 1978, p. 23). In a developing capitalistic society, market relations and the competition inherent in such a society become an all-pervasive influence on the reciprocal relationship between man and society. In a Marxian analysis, the economic relationship is basic, because the "subjugation and exploitation of man by man" is the source of alienation (Schaff, 1970, pp. 105123). It is thus by means of this reciprocal relation and subjugation that man can become alienated from his species.

In order to explain our choice of societal variables (and differentiation of these from structural variables), we must backtrack a bit. Social work, perhaps more than any other profession, is organized, funded by, and thus largely controlled by local, state, and federal government. The specific ways in which society views and treats the institution of social work are elements we have chosen to call 
societal variables. We are viewing them separately from structural variables in an attempt to operationalize Marx's idea of "alienation from the species," as well as more recent literature dealing with social workers as agents of social control (see Brager \& Halloway in the review of the literature).

Our decision to separate structural from societal variables is based on our desire to articulate the various sources of environmentally induced alienation. Structural alienation refers to the immediate work environment, that is, how the job is arranged. Societal alienation measures the place of social services in the society at large. In a capitalist economy, there is likely to be tension between the society and social services since the free market is believed to be self-regulating and little need is seen to help people who cannot make it on their own. Thus, social services in a capitalist society are viewed not as a required institution for the functioning of society, but rather as a safety net when other institutions fail to meet their obligations. In other words, social services in a capitalist economy are residual in nature and thereby often stigmatize the recipients of such services as well as the agencies and workers who serve them.

The variables in Table $\mathrm{V}$ were chosen to indicate objective sources of societal alienation. The variables "stable funding" and "limited resources" represent concrete 
ways in which society can show support for social services and for social service workers. The variables "choice of clients" and "clients with severe economic problems" were chosen to explore Brager and Halloway's (1978) position. These authors and others contend that social workers are agents of social control and deal with a population not functioning in society, due in large part to the inherent arrangements of capitalism.

TABLE V

SOCIETAL ALIENATION: FREQUENCY OF RESPONSES IN PERCENT ${ }^{a}$

\begin{tabular}{|c|c|c|c|c|c|}
\hline Variables ${ }^{\mathrm{b}}$ & $\begin{array}{c}\text { Percent } \\
\text { High } \\
\text { Aliena- } \\
\text { tion } \\
\end{array}$ & $\begin{array}{c}\text { Percent } \\
\text { Moderate } \\
\text { Aliena- } \\
\text { tion } \\
\end{array}$ & $\begin{array}{c}\text { Percent } \\
\text { e Low } \\
\text { Aliena- } \\
\text { tion } \\
\end{array}$ & $\begin{array}{c}\text { Total } \\
\text { Percent }\end{array}$ & $\mathrm{n}$ \\
\hline $\begin{array}{l}\text { Choice of clients/people to } \\
\text { work with }\end{array}$ & 66.2 & 21.9 & 14.0 & 100 & 467 \\
\hline $\begin{array}{l}\text { Clients with severe economic } \\
\text { problems }\end{array}$ & 63.7 & 26.1 & 10.2 & 100 & 459 \\
\hline Limited community resources & 42.6 & 38.6 & 18.8 & 100 & 455 \\
\hline Unstable funding & 31.0 & 45.8 & 23.2 & 100 & 461 \\
\hline
\end{tabular}

aigh alienation means a response of very descriptive and somewhat descriptive; moderate alienation means a response of somewhat descriptive and somewhat not-descriptive; low alienation means a response of not-descriptive or very not-descriptive.

${ }^{b}$ Some items were reworded to facilitate presentation. Refer to the questionnaire in the Appendix for the original wording of items.

As shown in Table V, 66.2 percent of the respondents found "no choice of clients" descriptive of their jobs. In response to "clients with severe economic problems," 63 percent of the respondents found this highly descriptive of their work. "Limited resources" was considered as 
descriptive of their work by 42.6 percent of the respondents. Finally, "unstable funding" was found as a highly alienating factor in 31 percent of the respondents.

It is clear from these results that societal variables play a significant role in social service work and alienation among social service workers. Over 60 percent of those sampled were highly alienated in regard to choice over their clients, and clients who were beset with severe economic problems. This suggests a lack of autonomy and control over whom social services serve. Most importantly, the responses conform to Brager and Halloway's (1978) position that social workers are agents of social control and that conflicts in the larger society also have an impact on social workers and organizations. Client variables appear to be a significant aspect of societal alienation.

Lack of external support systems was also an important factor in objective societal alienation in social service workers. "Limited resources" (42.6 percent) and "unstable funding" (31 percent) illustrate that society's support for social services is minimal at best. This is indicative of Marx's concept of "alienation from the species." Many social service workers are apparently alone in their uphill struggle to help those members of society who have been excluded from the benefits of capitalism. Here we see social service workers caught in the midst of conflicting ideologies and values. The society at large condones aiding the 
needy and yet is not willing to appropriate sufficient tax monies for this express purpose. Social service workers are indeed in the midst of the conflicts inherent in the larger society, and thereby their work is highly conducive to alienation, in particular, "alienation from the species."

\section{SUBJECTIVE ALIENATION \\ (DEPENDENT VARIABLE)}

Subjective alienation refers to the expressed conscious feelings and attitudes that people have about their work. In designing the items used on the questionnaire, we wanted to elicit responses indicating a person's feelings and attitudes about her/his job. In formulating statements to measure this concept, we drew on a number of sources. From Marx we focused on the ideas of alienation from others, from the work process, and from the product of one's labor. Archibald (1976), following Marx, separates alienation into four dimensions: (1) feelings of detachment from work, (2) feeling that work is a means to an end, (3) feelings of misery and powerlessness, and (4) feelings of selfestrangement. Seeman (1959) views alienation in terms of powerlessness, meaninglessness, normlessness, and selfestrangement. From Schacht we took the idea that Marx's categories could be operationalized as:

- dissatisfaction with one's job, experiencing of one's work as not being intrinsicly rewarding, and experiencing work as being insufficiently selfdirected, meaningful and self-expressive. (1971, p. 171) 
Using all of these theorists, we devised statements to determine the degree of alienation subjectively experienced by social service workers. For instance, the statement, "I get tired of listening," was used to measure the concept of alienation from others, that is, clients. Similarly, the statement, "My job is strictly a means to an economic end," was used to operationalize Archibald's "meansend" category (1976). Likewise, "Too many people dictate how my work is to be carried out," is an attempt to measure powerlessness and lack of autonomy. As a final example, "If I had to do it over, I would choose this job/career over again," is an overall measure of satisfaction with the present position of employment.

Table VI shows the percentage of responses in each of the three categories indicating high, moderate, or low alienation. From all of the eighteen measures of subjective alienation, our study focused on the four already noted.

The responses to each of these statements reflect a consistent pattern. Most respondents indicated moderate to low subjective alienation. Of the four measures, the statement, "If I had to do it over, I would choose this job/ career over again," evidenced the highest amount of subjective alienation; 20.2 percent disagreed with the statement. Some 16.2 percent agreed that "Too many people dictate how my work is to be carried out." Only 11 percent of the respondents agreed with the statement, "I get tired of 
TABLE VI

SUBJECTIVE ALIENATION: FREQUENCY OF RESPONSES IN PERCENT ${ }^{a}$

\begin{tabular}{lccccc}
\hline \multicolumn{1}{c}{ Percent Percent Percent } & & \\
Variables & High & Moderate & Low & & \\
Aliena- Aliena- Aliena- & Total & & \\
tion & tion & tion & Percent & n \\
\hline Would not choose career again & 20.2 & 30.1 & 49.6 & 100 & 475 \\
Tired of listening & 11.9 & 47.8 & 40.3 & 100 & 477 \\
Too many dictate & 16.2 & 35.5 & 48.3 & 100 & 462 \\
An economic end & 6.5 & 27.5 & 66.0 & 100 & 477 \\
\hline
\end{tabular}

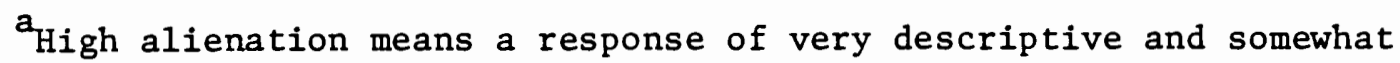
descriptive; moderate alienation means a response of somewhat descriptive and somewhat not-descriptive; low alienation means a response of not-descriptive or very not-descriptive.

${ }^{b}$ Some items were reworded to facilitate presentation. Refer to questionnaire in the Appendix for the original wording of items.

listening." Finally, very few indicated that they were only economically motivated by their jobs; 6.2 percent agreed that it was "a means to an economic end."

Most social service workers, as evidenced by only 6.5 percent of the respondents stating that the job was only "a means to an economic end," found their jobs intrinsicly rewarding. Concomitantly, 20.2 percent stated they "would not choose career again," which indicates that the majority of social service workers are satisfied with their work. Some 16.2 percent indicated that "too many dictated" their work, illustrating a feeling of alienation from management or powerlessness. However, the majority of workers feel that they have some degree of power or control over their work. 
Overall, the results of our measurements indicate that there is little conscious expression of subjective alienation. This is in agreement with our first hypothesis which stated that we would find more structural and societal alienation than subjective alienation.

The principle of cognitive dissonance can be an illuminating concept in regard to the above responses to our subjective measures. Cognitive dissonance refers to a situation in which a person holds onto two beliefs or cognitions which are in opposition to one another (Selltiz et al., 1976, p. 576). To understand the importance of this concept, we need to consider that social service workers are socialized through their profession and educational experiences to believe in a humanitarian and altruistic philosophy. However, this belief system is incompatible with allowing oneself to express alienation from others. As an example, reporting "I am tired of listening" is inconsistent with the professional values that one is to be warm, genuine, and empathetic with one's clients. As noted above, only 11 percent responded in the affirmative to this phrase. Herein, however, we must be cautious as numerous studies have shown (Selltiz et al., 1976) that verbal reports (or subjective measures) are poor predictors of a person's behaviors. This fact underscores the importance of utilizing objective as well as subjective measures of alienation. 
In lieu of the overall low expression of subjective alienation, we refer to our review of the literature and Finifter's objection to relying on subjective measures alone:

- . presumably, many have been socialized to expect no more than they actually received; therefore, felt content and did not subjectively experience dissatisfaction or alienation...

and this he referred to as "false consciousness" (1972, p. 6). Perhaps, as Israel states, the "alienating processes are either so effective, or have been going on continuously for such a long period, that one no longer experiences them on a cognitive level" (1971, p. 80). The question which looms like a dark cloud over these results, is whether social service workers have so capitulated to the capitalistic system that they no longer experience alienation in an alienating environment.

\section{SOCIAL REALITY}

Our conception of social reality can best be understood by the Marxian concept of the "historical moment." Man, for Marx, cannot be viewed as separate from the society in which he lives. Within man's relationship to society Marx viewed the economic relationship as the basic source of alienation. Thus, there are certain conditions present in society at any given moment which greatly influence how people view their life situations, and of these conditions Marx saw market relations as the dominant and pervading force. The "historical moment," at the time of this study, 
is one of economic insecurity which manifests itself in conservatism and uncertainty. These forces are bound to impact how one views one's job. The reality of budget cuts in social service programs, for example, could lead to respondents feeling that they should not complain about their jobs because jobs in general are difficult to find.

As conceptualized above, it can be seen that social reality variables could play an important role in intervening and changing the relationship between our independent and dependent variables, that is, between the respondents' perception of objective work conditions (structural alienation) and the objective conditions of society (societal alienation) and their expressed feelings and attitudes about their job (subjective alienation). As stated in our third hypothesis, we believe that the current social reality of economic insecurity will serve to suppress the subjective expression of alienation from one's work.

Although there are numerous social reality variables stemming from the present "historical moment," we chose to limit our variables to those revolving around economic relationships as is central to Marx's paradigm. However, status concerns, professionalism, class consciousness, culture, and personality factors could all as well be important intervening variables. As such, our measures may be limited; yet, we feel that we are in keeping with a Marxist conception 
and, given our present economic conditions, that we will have tapped the most crucial variable--market relations.

Social reality was operationalized by utilizing Dahrendorf's (1959) measures for social mobility. These measures we viewed as tapping the potential for social mobility--a salient descriptive feature of the economic relations in the marketplace and therefore, social reality as it pertains to the individual's economic relationship to a capitalist society. The three measures used for social reality in relation to one's job were "few opportunities for advancement," "as good as I can expect," and "fair salary."

If one looks at one's job as "as good as can be expected," it is likely that the respondent will express less subjective alienation. Likewise, if workers feel there are "few opportunities for advancement" and that they receive a "fair salary" (again, keeping in mind that "fair" is mitigated by the current economic situation), they may suppress their feelings of dissatisfaction and alienation.

From Table VII it appears that many of the respondents believe that they have "few opportunities for advancement" and that their job is "as good as can be expected." Over 50 percent of the respondents saw these variables as highly descriptive of their situation. On the other hand, only 18.2 percent of the respondents agreed that "unfair salary" is highly descriptive of their situation. Thus, although social service workers believe there is not a good chance 
that they will advance, most believe that their salaries are pretty fair.

TABLE VII

SOCIAL "REALITY" AND HYPOTHESIZED ALIENATION: FREQUENCE OF RESPONSES IN PERCENT ${ }^{a}$

\begin{tabular}{|c|c|c|c|c|c|}
\hline $\operatorname{Variables}^{\mathrm{b}}$ & $\begin{array}{c}\text { Percent } \\
\text { High } \\
\text { Aliena- } \\
\text { tion } \\
\end{array}$ & $\begin{array}{c}\text { Percent } \\
\text { Moderate } \\
\text { Aliena- } \\
\text { tion }\end{array}$ & $\begin{array}{l}\text { Percent } \\
\text { e Low } \\
\text { Aliena- } \\
\text { tion } \\
\end{array}$ & $\begin{array}{c}\text { Total } \\
\text { Percent }\end{array}$ & $\mathrm{n}$ \\
\hline $\begin{array}{l}\text { Few opportunities for } \\
\text { advancement }\end{array}$ & 50.3 & 34.3 & 15.4 & 100 & 455 \\
\hline As good as I can expect & 50.2 & 33.4 & 16.4 & 100 & 479 \\
\hline Unfair salary & 18.2 & 36.5 & 45.3 & 100 & 479 \\
\hline
\end{tabular}

High alienation means a response of very descriptive and somewhat descriptive; moderate alienation means a response of somewhat descriptive and somewhat not-descriptive; low alienation means a response of not-descriptive or very not-descriptive.

${ }^{b}$ Some items were reworded to facilitate presentation. Refer to questionnaire in the Appendix for the original wording of items.

In sum, we found that 50 percent of our respondents, who we hypothesize are highly alienated, feel resigned to their jobs and do not have optimism regarding improvement. However, that same group feels that their salaries are fair. It is here that we see Marx's "historical moment" at play, and how that works to inhibit one's expression of alienation. There is a sense of futility shown here that one cannot do better and therefore must accept what $s /$ he receives as fair. These responses attest to the significance of current socio-political realities and how our intervening variable could affect the relationship between the subjective expression of alienation and those objective work and 
societal conditions which contribute to its expression. Apart from more philosophic and desirable notions of social reality, current conditions and economic exigencies can play an important role in determining the extent to which an individual expresses conscious feelings of alienation.

\section{SUMMARY}

In this chapter, we attempted to define and describe our variables. As set forth in the objectives of our study, we hypothesized that we would find more structural and societal alienation than subjective alienation. What did we actually find?

Our respondents were quite low in expressing subjective alienation, which was as hypothesized. Alienating responses to societal measures of alienation were significantly higher than to the subjective measures. Although the structural measures were slightly higher in alienating responses than subjective, they were less than we had anticipated. Social reality factors appear to be a significant variable due to the high frequency of hypothesized alienating responses. Overall, societal measures indicated the highest level of alienation. This gives support to Brager and Halloway's (1978) contention that social workers are imbued in the conflicts of the larger society, and also illustrates that Marx's conception of alienation from the species is an important aspect of alienation among social 
service workers. Social measures are followed by social reality, structural alienation, and lastly, subjective alienation in frequency of alienating (or hypothesized alienation/social reality) responses.

Our data lend support to our first hypothesis that we would find more structural and societal alienation than subjective alienation. However, the difference between our societal and structural measures (our independent variables) is striking. The objective factors of the work place seem to be of less importance to social service workers than we anticipated, and societal factors, in terms of frequency of alienating responses, were much more potent.

From these data, it appears that societal forces for social service workers are a significant variable in terms of alienation. Perhaps in view of the special nature of social services in the society at large and its dependence upon society sanctions and funds, social service workers are impacted more by these variables than the immediate work environment.

Subjective alienation was low in alienating responses, as we had predicted. To explain the low frequency in alienating responses, we referred to the idea of "false consciousness" (Finifter, 1972, p. 6), in which people have been "socialized to expect no more than they receive; therefore [they] did not subjectively experience dissatisfaction or alienation." Furthermore, as previous studies (Selltiz, 
1976) have indicated, subjective self-reports are poor predictors of behavior. This illustrates the dire need (as set forth by Marxist thought) for objective as well as subjective measures in studying alienation.

Overall, our sample was not highly alienated; however, our data support our first hypothesis: we will find more structural and societal alienation than subjective alienation. In the following chapters we will examine our second and third hypotheses, which state there will be an association between structural/societal alienation and subjective alienation, and the difference between the acknowledged structural/societal alienation and the subjective expression of alienation will be due to social reality. 
CHAPTER IV

THE RELATIONSHIP BETWEEN STRUCTURAL/SOCIETAL ALIENATION AND SUBJECTIVE ALIENATION

\section{INTRODUCTION}

The findings in Chapter III supported the hypothesis that more structural/societal alienation will be reported than subjective alienation. These findings are particularly important because they not only verify that work alienation consists of objective and subjective components, but also they support the contention that the objective conditions cannot be ignored in studying alienation from work.

Theoretically we have conceptualized that structural and societal alienation will lead to the subjective experience on the part of the worker of that alienation. The purpose of Chapter IV is to examine if there is indeed any association between structural/societal alienation and subjective alienation.

In working toward this end, we employed the gamma statistic to determine the existence and the degree of association between the certain structural, societal, and subjective measures of alienation discussed in Chapter III. The reader may recall that gamma measures the rank of one respondent relative to another on any two variables. 
Gamma is also a measure of proportionate reduction in error.

In looking at zero-order correlations, we will refer to gammas below .25 as indicative of little or weak association, gammas at or around .25 as indicative of a moderately strong association, and gammas above or well above .25 as indicative of a strong relationship.

\section{STRUCTURAL ALIENATION BY}

SUBJECTIVE ALIENATION

At the outset of the study we predicted that a positive relationship will exist between structural alienation and the subjective expression of alienation. Table VIII demonstrates that this relationship certainly does exist. The gamma coefficient between the three measures of structural alienation, and the four measures of subjective alienation indicate a high positive association. Only the structural measure "learn new things" does not completely fulfill our prediction. While this variable is strongly related to two measures of subjective alienation, it is only weakly related to "too many people dictate" and "tired of listening."

As we had predicted, having access to the administration in the work place, indicative of having some control over the process and the product of one's work, is an important characteristic of non-alienated work. Having an opportunity to learn new things on the job and being able to 
TABLE VIII

STRUCTURAL ALIENATION BY SUBJECTIVE ALIENATION: GAMMA COEFFICIENT

\begin{tabular}{llll}
\hline \multicolumn{1}{c}{ Measures of } & \multicolumn{1}{c}{ Measures of } & & \\
Structural Alienation & Subjective Alienation & Gamma & n \\
\hline Access to administration & Too many people dictate & .43 & 431 \\
Access to administration & An economic end & .39 & 436 \\
Access to administration & Tired of listening & .28 & 438 \\
Access to administration & Choose career again & .24 & 433 \\
& & & \\
Learn new things & Choose career again & .36 & 475 \\
Learn new things & An economic end & .35 & 477 \\
Learn new things & Too many people dictate & .13 & 462 \\
Learn new things & Tired of listening & .11 & 476 \\
Unclear expectations & Too many people dictate & .38 & 454 \\
Unclear expectations & An economic end & .37 & 466 \\
Unclear expectations & Choose career again & .32 & 465 \\
Unclear expectations & Tired of listening & .21 & 468 \\
\hline
\end{tabular}

utilize one's creativity appear to be related to whether people would be likely to choose to work in social services again and whether they see their job merely as a way to pay the bills. Similarly, when expectations of the tasks are unclear, then it is likely that these workers will express alienation from others and from their work. This supports Marx's own argument that elements such as "creative activity," "control," and "relatedness to the self and others" are essential for non-alienated work.

\section{SOCIETAL ALIENATION AND \\ SUBJECTIVE ALIENATION}

We have also predicted that societal alienation will be associated with subjective alienation. Table IX illustrates that there is a high positive correlation between 
the subjective experience of alienation and societal variables. The gamma coefficient between the societal variables "choice of clients" and "clients with severe economic problems" and the subjective experience variables range from .28 to .66 , indicating high positive correlation. The gamma between "limited community resources" and the subjective measures range from .16 to .25 and indicate a moderate degree of association. On the other hand, "stable funding" shows no association with the subjective variables; the gammas range from -.06 to .00 . Thus it would appear that this variable has no impact upon the subjective experience of alienation. This is consistent with the notion that social workers are very much considered agents of social control. Funding may be stable, but hardly adequate to implement real changes; monies are only stable enough to continue maintenance of the status quo.

It is important to remember that the respondents were answering the questionnaire prior to knowledge of the scope and impact of President Reagan's budget cuts upon the social services. It would be interesting to examine the effects of the "stable funding" variable in future studies.

It appears that having a lack of choice over clients, lacking available resources, and working with clients with severe economic problems are three factors that may produce a good deal of conscious alienation. This again is consistent with the contention that social workers are agents of 
TABLE IX

SOCIETAL ALIENATION BY SUBJECTIVE ALIENATION:

GAMMA COEFFICIENT

\begin{tabular}{llcc}
\hline \multicolumn{1}{c}{ Measures of } & \multicolumn{1}{c}{ Measures of } & & \\
Societal Alienation & Subjective Alienation & Gamma & n \\
\hline Choice of clients & An economic end & .66 & 461 \\
Choice of clients & Too many dictate & .50 & 448 \\
Choice of clients & Choose career again & .45 & 460 \\
Choice of clients & Tired of listening & .24 & 462 \\
& & & \\
Severe economic problems & Too many dictate & .42 & 440 \\
Severe economic problems & Tired of listening & .37 & 455 \\
Severe economic problems & An economic end & .37 & 453 \\
Severe economic problems & Choose career again & .28 & 453 \\
& & & \\
Limited community resources & Too many dictate & .25 & 440 \\
Limited community resources & Tired of listening & .18 & 452 \\
Limited community resources & Choose career again & .17 & 450 \\
Limited community resources & An economic end & .16 & 451 \\
& & & \\
Stable funding & Too many dictate & .00 & 450 \\
Stable funding & Choose career again & .00 & 454 \\
Stable funding & An economic end & -.05 & 455 \\
Stable funding & Tired of listening & -.06 & 457 \\
\hline
\end{tabular}

social control (Brager \& Halloway, 1978); they are engaged in jobs that must keep nonfunctional people "in line."

Brager and Halloway further propose that alienation results from the societal conflicts that are embedded in the field of social services. Social service workers who are expected to help the needy, yet find themselves severely restricted by what services they can actually provide, find themselves as pacifiers (and as agents of social control), and thus experience alienation. Our study would appear to support this view of the function of social services in the United States. 
In summary, our initial findings support the original hypothesis that the conditions of the work place (structual) and the conditions of the social structure (societal) are predictive of the subjective experience of alienation from work. These data lead us to a critical view of the trend in social services to place emphasis upon individualized solutions such as workshops. Moreover, these types of solutions follow the paradigm of the implementation of social services in the United States. It is the individual who is seen as having the problem. As individuals, social workers, as much as their clients, are victims of the same social system, and are in the same manner held accountable for their individual distress. It is naive thinking to assume that the objective conditions of the world in which we live, including the work place, do not have impact upon the individual.

Therefore, we contend that subjective alienation, commonly referred to in the social services as "burnout," is not a phenomenon that stems from an individual worker's emotional incapacity. Its etiology is clearly connected to external circumstances. While we have not explored each respondent's psychological makeup, we do know that personality factors alone cannot account for alienation from one's work. Further, as is apparent, the subjective experience of alienation does not exist in a vacuum, but is strongly influenced by structural and societal conditions; 
so too, these latter variables do not seem to function independently of each other. Where we can predict subjective alienation, we will see structural and societal alienation. 


\section{CHAPTER V}

\section{STRUCTURAL ALIENATION VERSUS \\ SOCIETAL ALIENATION}

\section{INTRODUCTION}

In Chapter IV we found that the conditions of the work place (structural) and the conditions of the social structure (societal) are both predictive of the subjective expression of alienation from work.

In this chapter, we examine the relative importance of structural vs. societal in leading to feelings of work alienation. That is, are structural conditions or societal issues more predictive of the conscious expression of alienation? This will be done by (a) controlling for the four societal factors when measuring the association between structural and subjective alienation, and (b) controlling for the three structural variables when measuring the association between societal and subjective alienation.

The zero-order gammas will be compared to the secondorder gammas to see how the introduction of a control variable affects the strength of association between the structural/societal and subjective alienation.

In looking at the second-order correlations, we will consider gammas that increase 5 percentage points as 
indicative of an important additional proportional reduction in error regarding our prediction of the rank ordering of the independent and dependent variables. The converse is true for gammas that decrease 5 percentage points and more. If the second-order gammas go down, we can hypothesize that the control variable is responsible for changing the relationship between the independent and dependent variables. In order to facilitate our discussion of the tables, we chose to focus on the second-order gamma coefficients that have decreased 5 percentage points. This will give us an overall perspective of the influence of the control variable on the independent and dependent variables.

\section{STRUCTURAL VERSUS SOCIETAL}

Tables X-XIII illustrate the zero-order and secondorder gammas for the structural by subjective alienation and controlling for societal alienation.

Among those respondents who are in circumstances of high structural alienation, thirty-six of the forty-eight (75 percent) partial gammas are lower than their corresponding zero-order gammas. This suggests that for those who are highly alienated structurally, societal factors are at least as important as the structural measures in contributing to the subjective expression of alienation.

Eighteen of forty-eight (38 percent) of the partial gammas decrease for those who are in circumstances of 


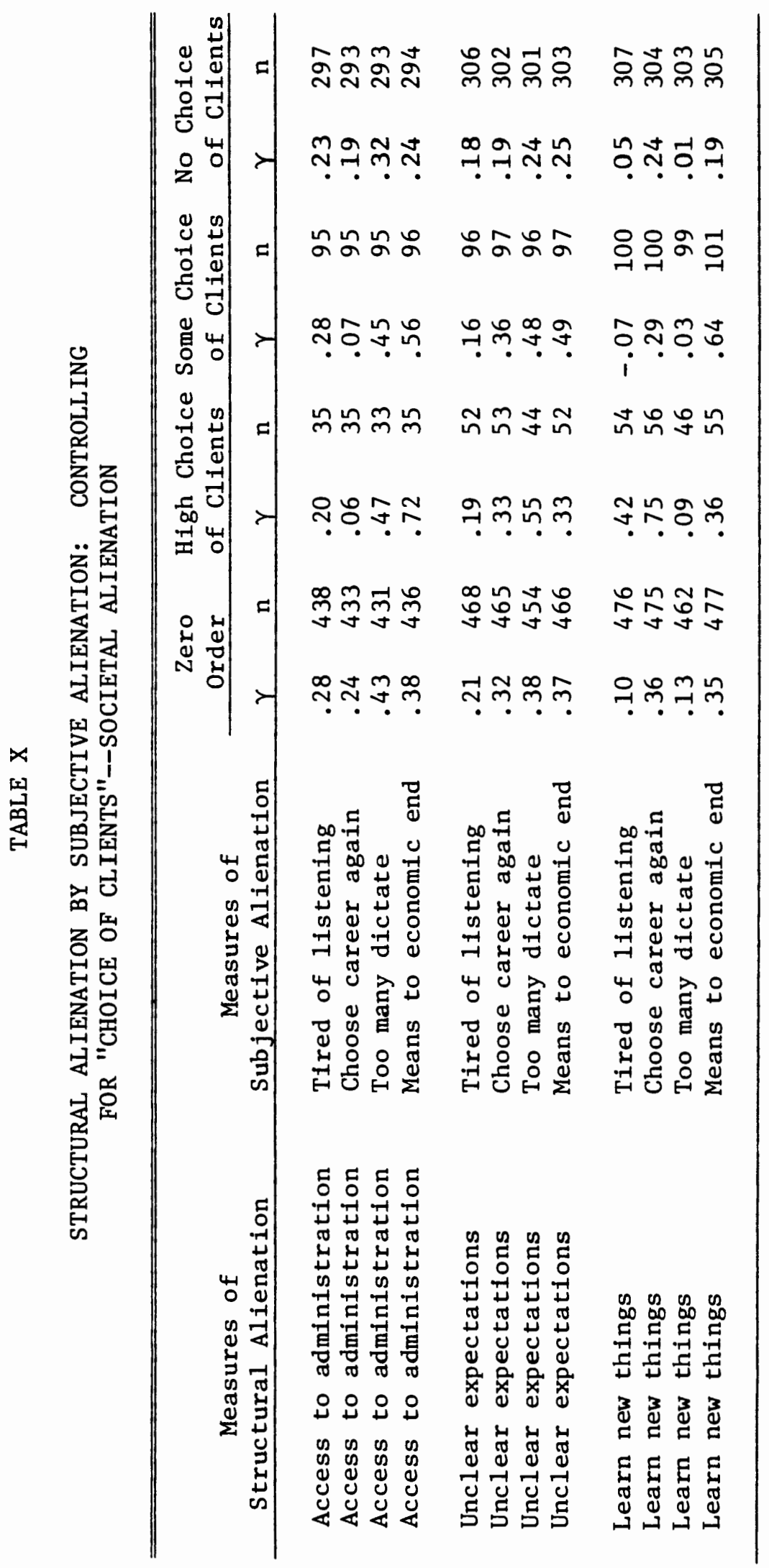




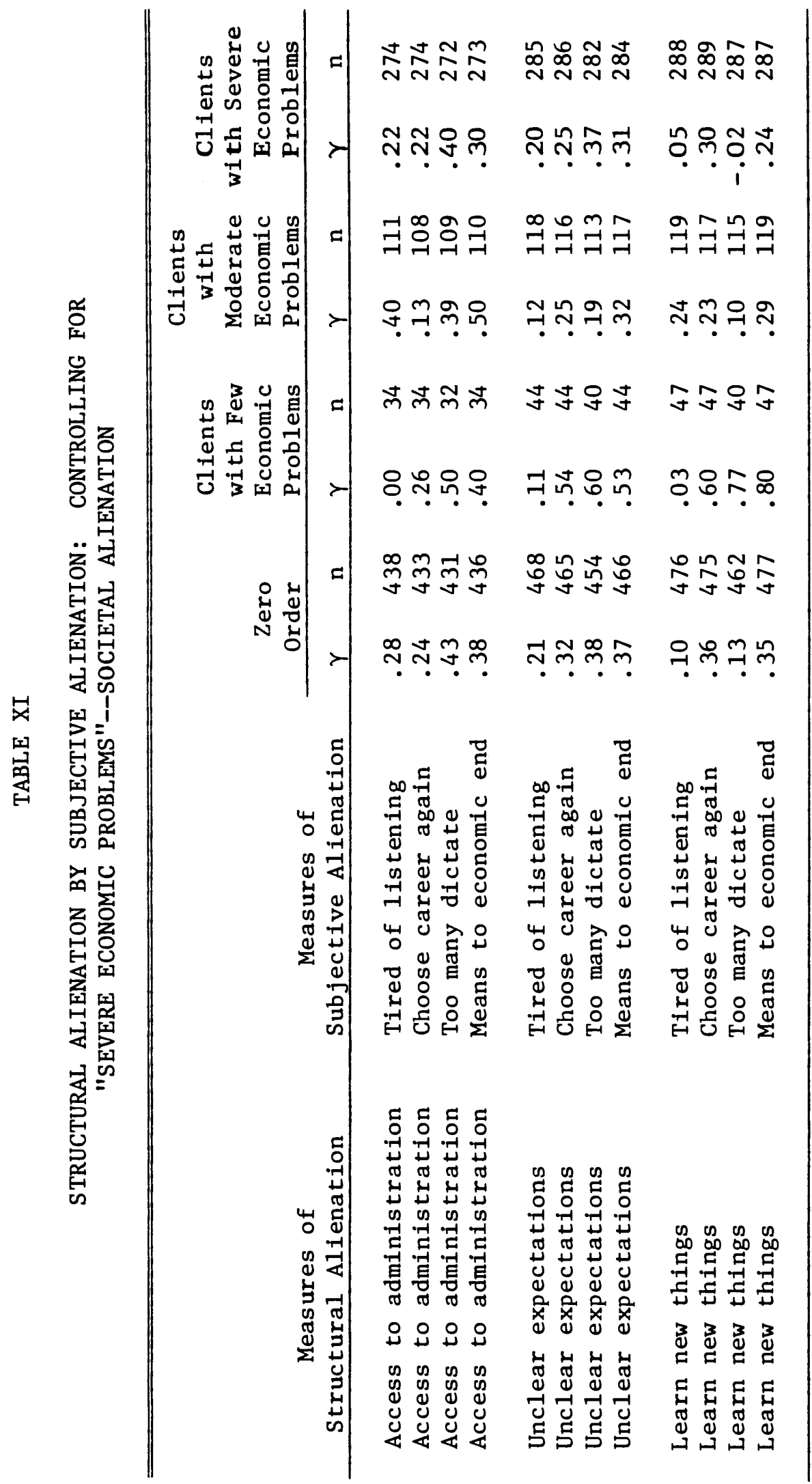




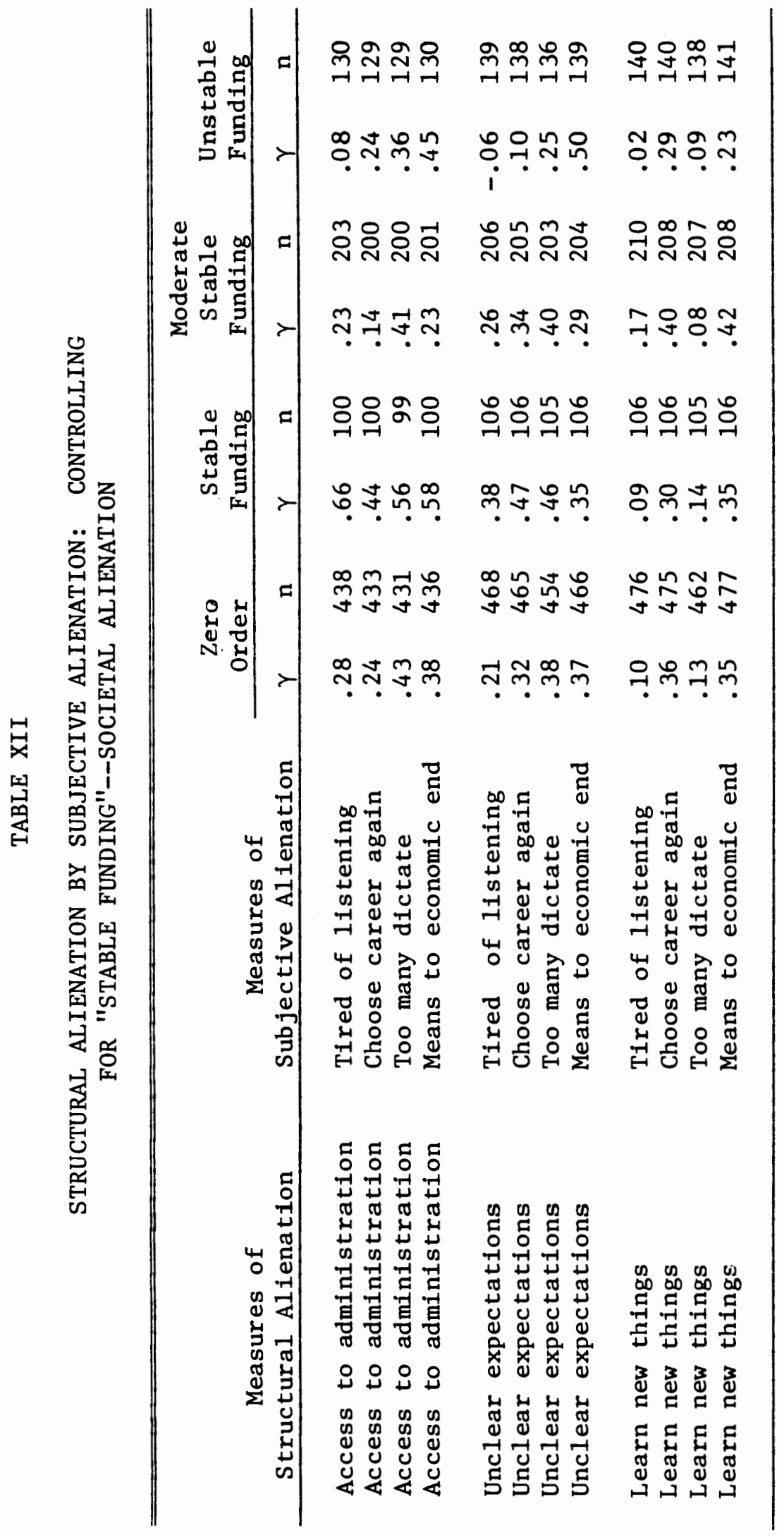




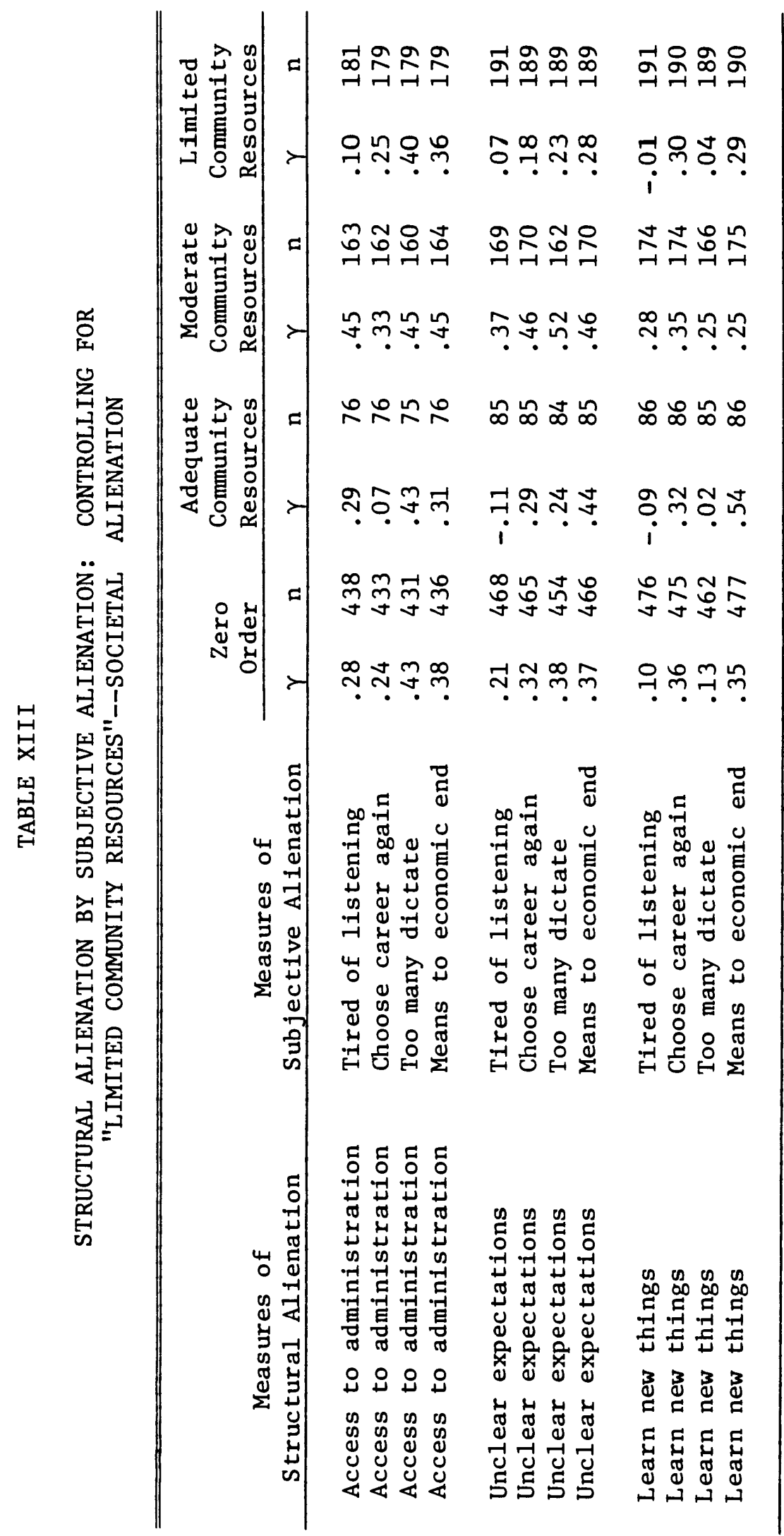


medium structural alienation. The basic trend is that of moderate influence in three of the four control variables (societal alienation). More specifically, the exception is "limited community resources," which has only one lower second-order gamma. This indicates that for the respondents who are moderately alienated structurally, having limited community resources is of less importance than the other three societal variables in mediating the relationship between structural and subjective alienation.

For the respondents who are in circumstances of low structural alienation, the control variables become less influential. Only twelve of the forty-eight (25 percent) of the partial gammas decrease. However, in contrast to the respondents in circumstances of moderate structural alienation, these respondents do indicate that having an insufficient number of community resources is an important factor. In summary, the data from Tables X-XIII continue to suggest that societal issues play an important role in the conscious expression of alienation. This appears to be especially true for those social service workers who are high in the expression of alienation. The societal measures of alienation are at least as important as the structural measures in contributing to the expression of burnout/ alienation for social service workers. As our respondents become more alienated, the influence of the structural variables appears to decrease. 
Tables XIV-XVI illustrate the zero-order and secondorder gammas for the societal by subjective alienation. We controlled for societal measures of alienation.

These tables indicate that among those who are in circumstances of high societal alienation, thirty-one of the forty-eight (65 percent) partial gammas are lower than their corresponding zero-order gammas. For these respondents, all three of the control variables have an equally important influence on the association between the independent and dependent variables. This suggests that the structural variables are as important as the societal measures of alienation in leading to the psychological expression of alienation.

Fifty-four percent, or twenty-six of the forty-eight partial gammas, decrease in the second-order gammas for the respondents who found themselves in circumstances of moderate societal alienation. Having an opportunity to "learn new things" on the job and having clear expectations from others appear to be the two important conditions for these respondents.

Finally, for the respondents who found themselves in circumstances of low societal alienation, only twelve of the forty-eight (25 percent) of the partial gammas decrease. "Unclear expectations" is clearly the control variable which has the greatest effect on mediating the original asssociation between the dependent and independent variables. The 


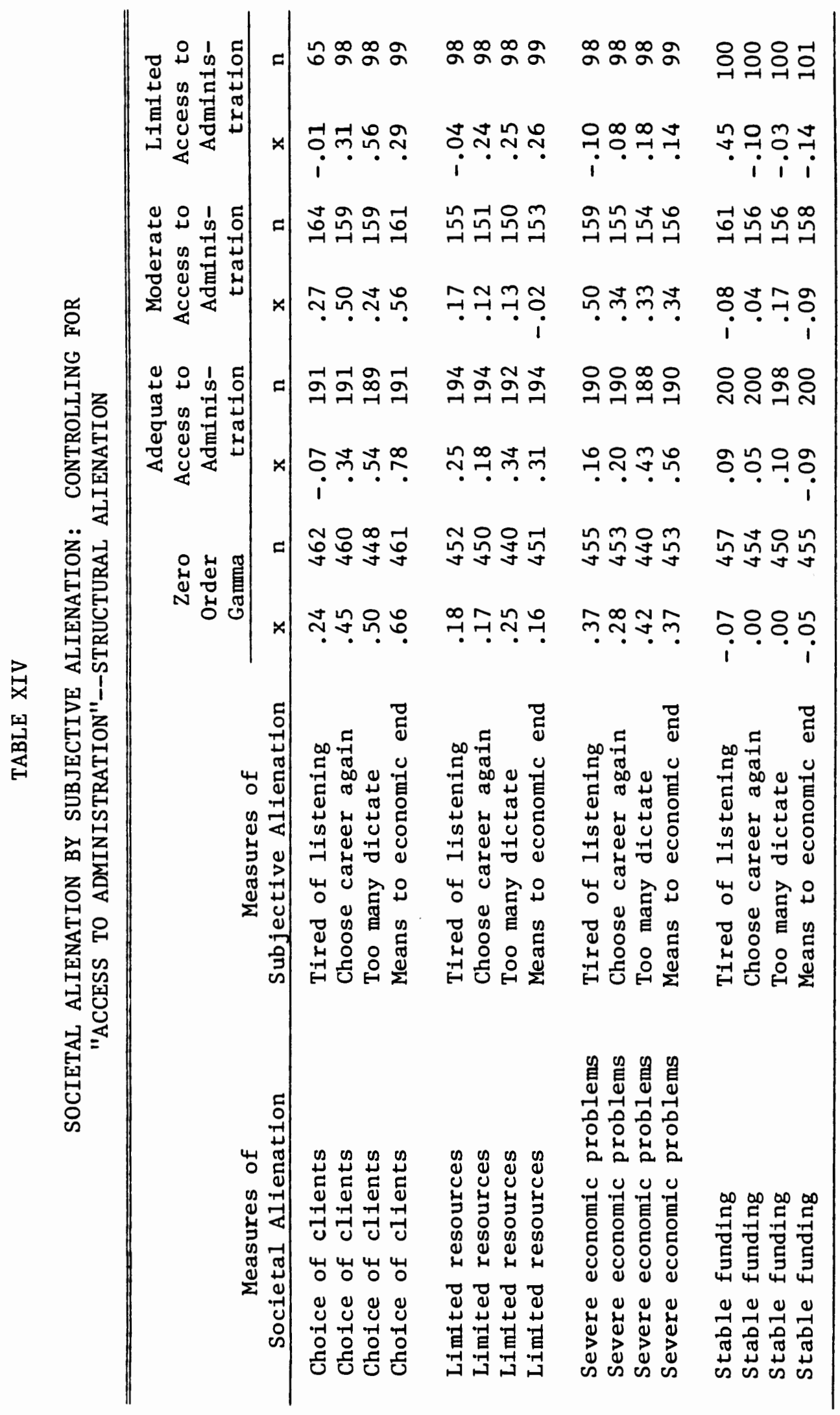




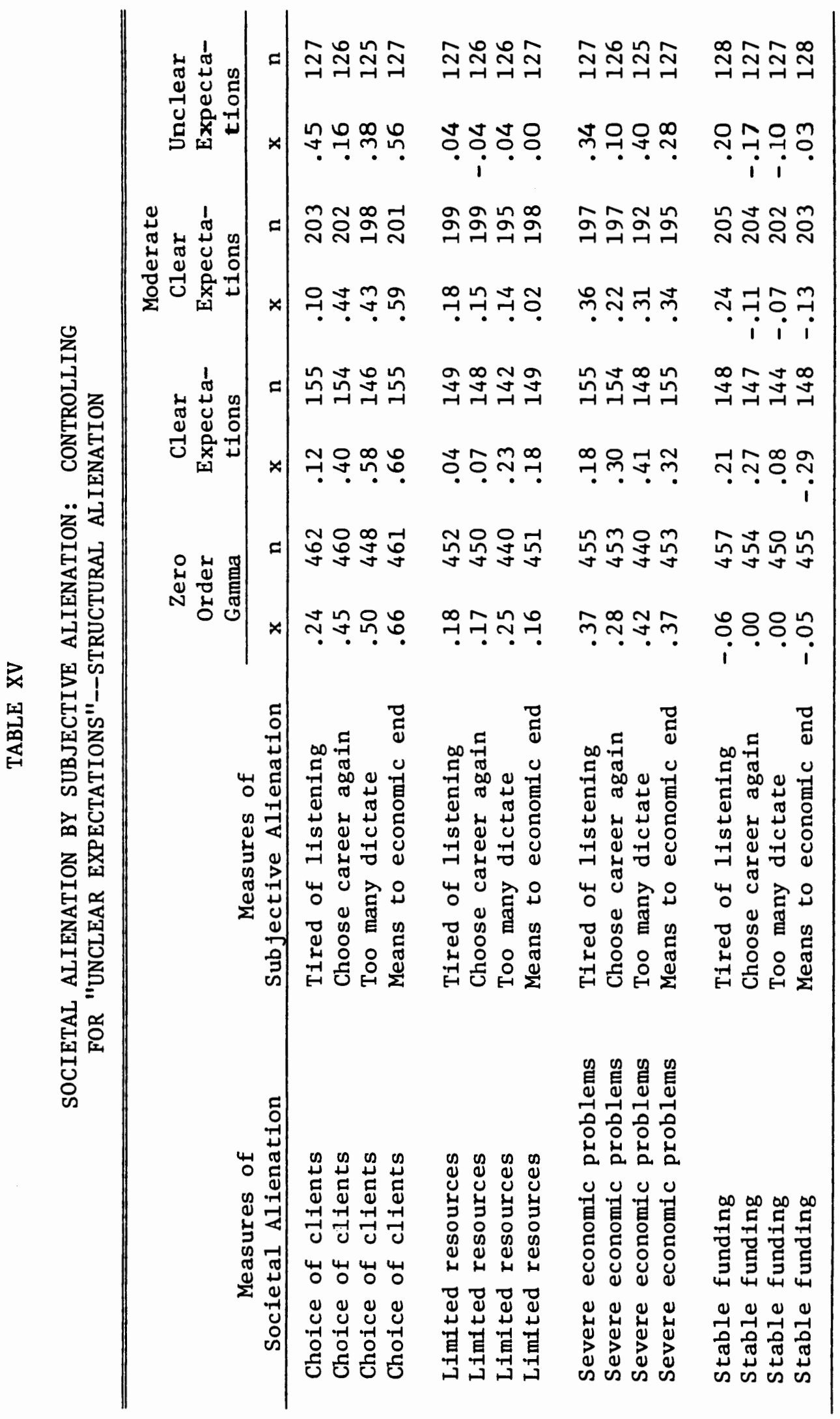




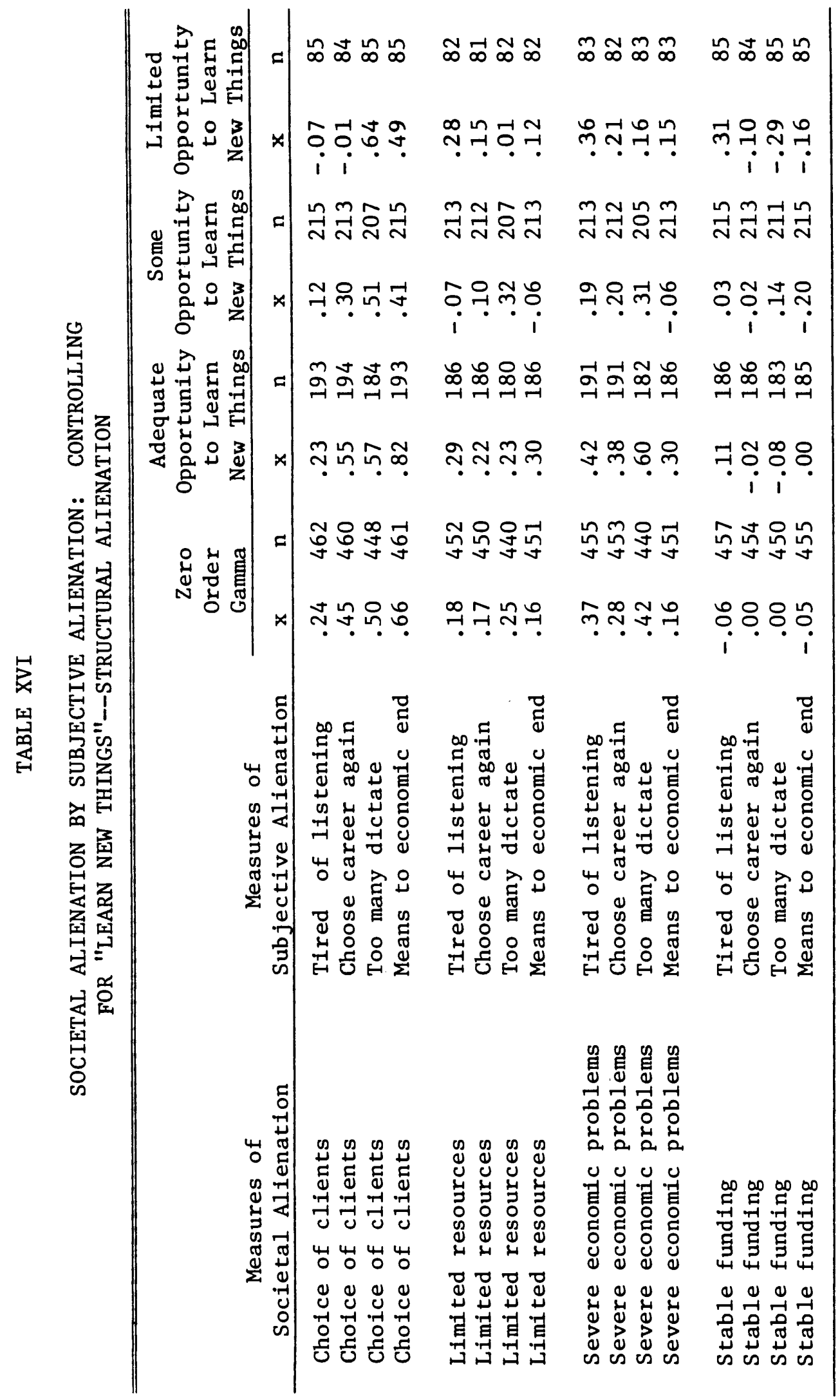


other two control variables ("access to administration" and "learn new things") play a very minor role.

Overall, the data from Tables XIV-XVI suggest that structural or organizational conditions do contribute to the experience of worker alienation. And again we find that the control variables (structural, in this case) seem to have the most influence over those respondents who find themselves in situations of high societal alienation.

\section{SUMMARY}

In conclusion, our findings in this chapter very clearly illustrate that both structural and societal factors are important in predicting the subjective experience of alienation from work. However, from our findings we cannot say that structural or societal issues are more important in predicting our dependent variable. The measures appear to be interdependent and work together rather than independent from one another. This is very consistent with the Maxian concept of the "dialectical" relationship between micro and macro structures in society. That is, the organizations or the social institutions in our society are a product of the values and norms of that society. Wagner and Cogen describe how social services are dependent upon the larger society:

Social workers art given little power to aid clients vis-a-vis the institutions of society (places of employment, schools, law enforcement agencies, etc.) that impact most importantly against poor and working 
people. . Social workers operate in an extremely narrow sector of capitalist life and are given little power to counteract the oppression of their clients. $(1978, \mathrm{p} .40)$

Social service workers, it appears, will continue to experience feelings of alienation because they espouse values that are not consistent with the values of the larger society. It is of vital importance that social service workers understand how the conditions of the work place and the function of social work in a capitalist society are intimately connected with the political and economic structure of society. There are no hard and fast dividing lines between levels of social phenomena; they blend together. Ritzer states :

Dialecticians would admit that although the real world is a maze in flux, it is necessary to carve it up into its component parts and analyze the crucial connections among these various phenomena. This, in fact, is exactly what Marx did in his analysis of capitalism. (1981, p. 63) 


\section{CHAPTER VI \\ SOCIAL "REALITY"--AN INTERVENING \\ VARIABLE}

INTRODUCTION

The findings in Chapter $\mathrm{V}$ illustrate that both structural and societal issues lead to the subjective expression of alienation. These measures of alienation appear to be interdependent rather than functioning independently from one another; therefore, we were unable to say that conditions of the work place are more or less predictive of the subjective expression of alienation from work than the conditions generated by societal factors. At the onset of the study we hypothesized that the social reality variables are likely to influence the relationship between the independent and dependent variables. The social reality variables are: "few opportunities for advancement," "fair salary," and "job as good as any." These variables stem from the Marxian view of how the conditions of society influence man's relationship to self and others. For Marx, the economic relationships in society are the basic sources of alienation. At the time of this study the prevailing conditions are characterized by serious economic insecurity which manifests itself by political conservatism, and cutbacks in social 
service programs. These conditions are apt to influence how one views the job and may encourage social service workers to overlook alienating factors that may be connected with the work. The extensive budget cuts in social services could contribute to the respondents feeling that they ought not express dissatisfaction with their job. Hence, we think that the current social reality of economic insecurity will serve to suppress the subjective expression of alienation.

In this chapter we will attempt to examine whether the social reality variables may explain why there appears to be more structural/societal alienation than subjective alienation. We will be especially sensitive to changes in gammas of more than 5 percentage points and more specifically we will be looking at gammas that decrease by 5 percentage points or more. If the gammas decrease, the control variables (social reality in this instance) are predicting the expression of alienation on the job. The social reality factors suppress the influence of other structural/societal conditions in the conscious expression of work alienation. Because of the reality of the economic conditions in our society we hypothesize that the respondents will tend to express less job dissatisfaction and will be less conscious of the alienating structural factors that logically lead to work alienation.

Tables XVII-XIX illustrate the zero-order and secondorder gammas for the structural by subjective 
alienation controlling for the three social reality variables.

\section{NEGATIVE SOCIAL REALITY}

Among the respondents who have a negative social reality, that is, agree that they have little opportunity for advancement, who have an unsatisfactory salary, and who are dissatisfied with their job or who do not agree that their job is as good as any, there is a decrease of 5 percent in sixteen of the forty-eight ( 44 percent) partial gammas.

The basic trend is that of a moderate influence in two of the three variables. The exception is "unfair salary," which has only three lowered gammas to the six and seven decreased gammas for the other social "reality" variables. It is interesting that in this time of serious fiscal crisis and decrease in worker salary, social service workers still considered the pay they receive to be relatively fair. However, when we consider that our survey was conducted before the announcement of President Reagan's budget cuts, we can understand that social services may not have realized the extent of economic crisis.

\section{AMBIGUOUS SOCIAL REALITY}

A clear 50 percent of the second-order gammas decrease for the respondents who agree that they have some opportunity for advancement, are somewhat satisfied with their 


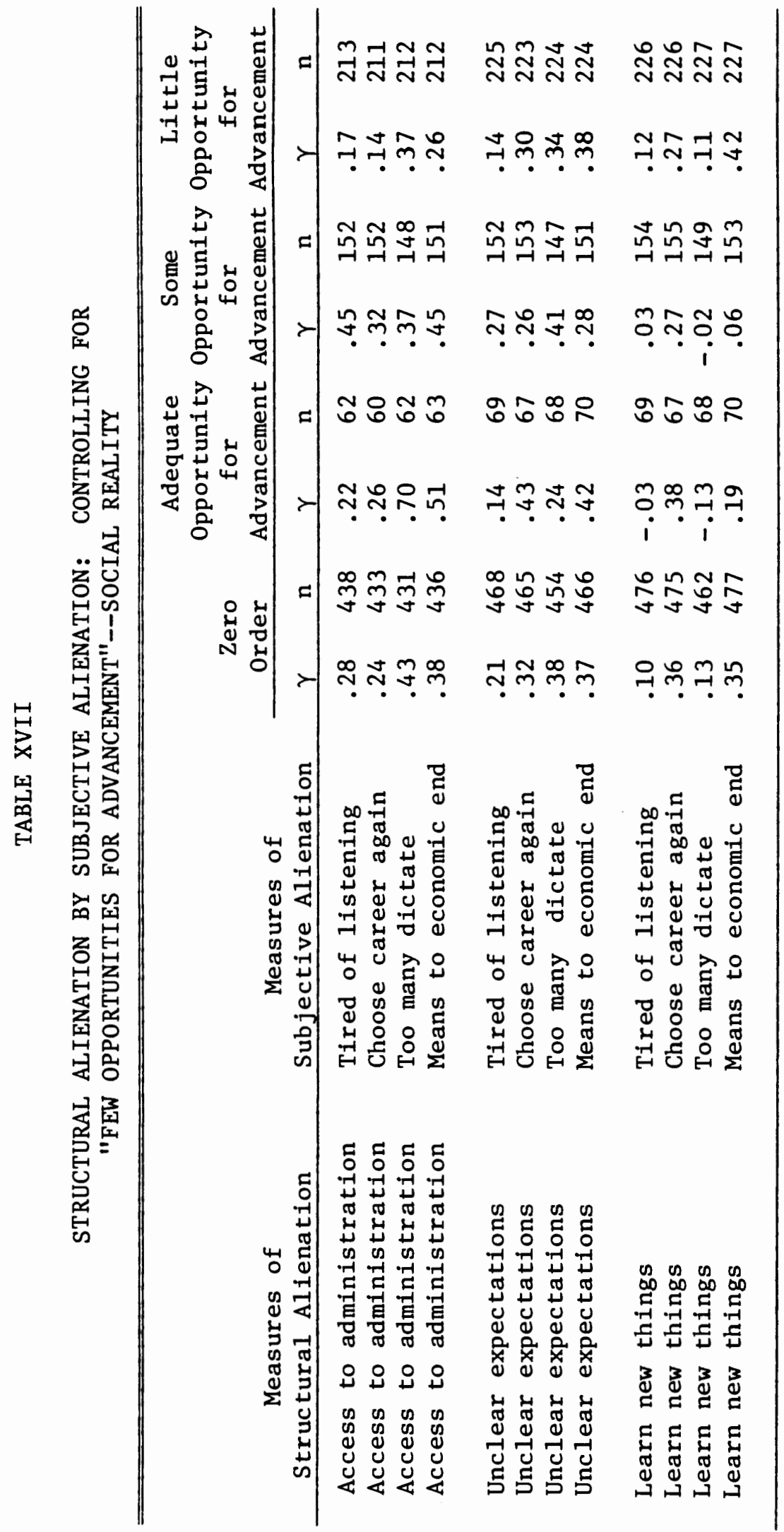




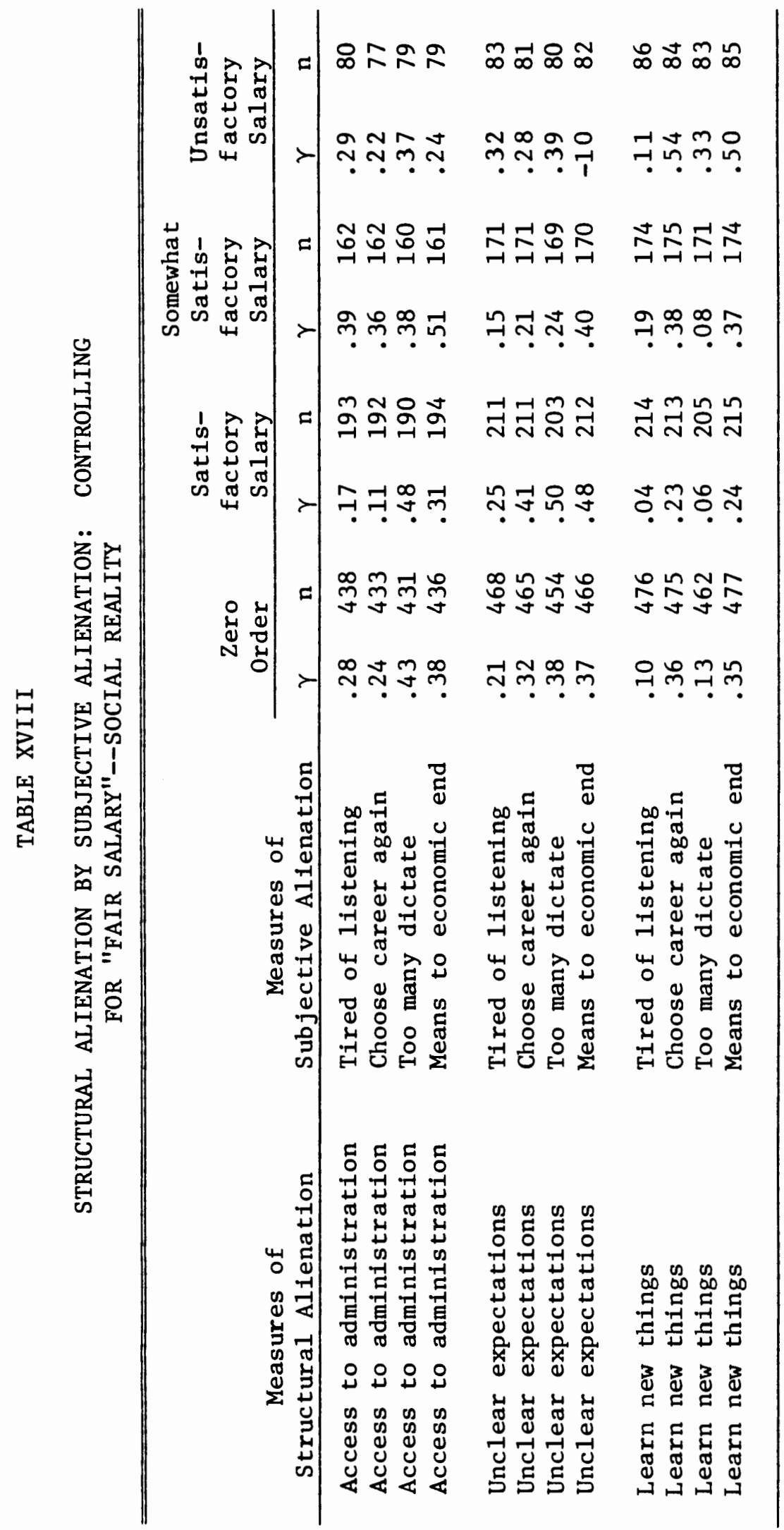




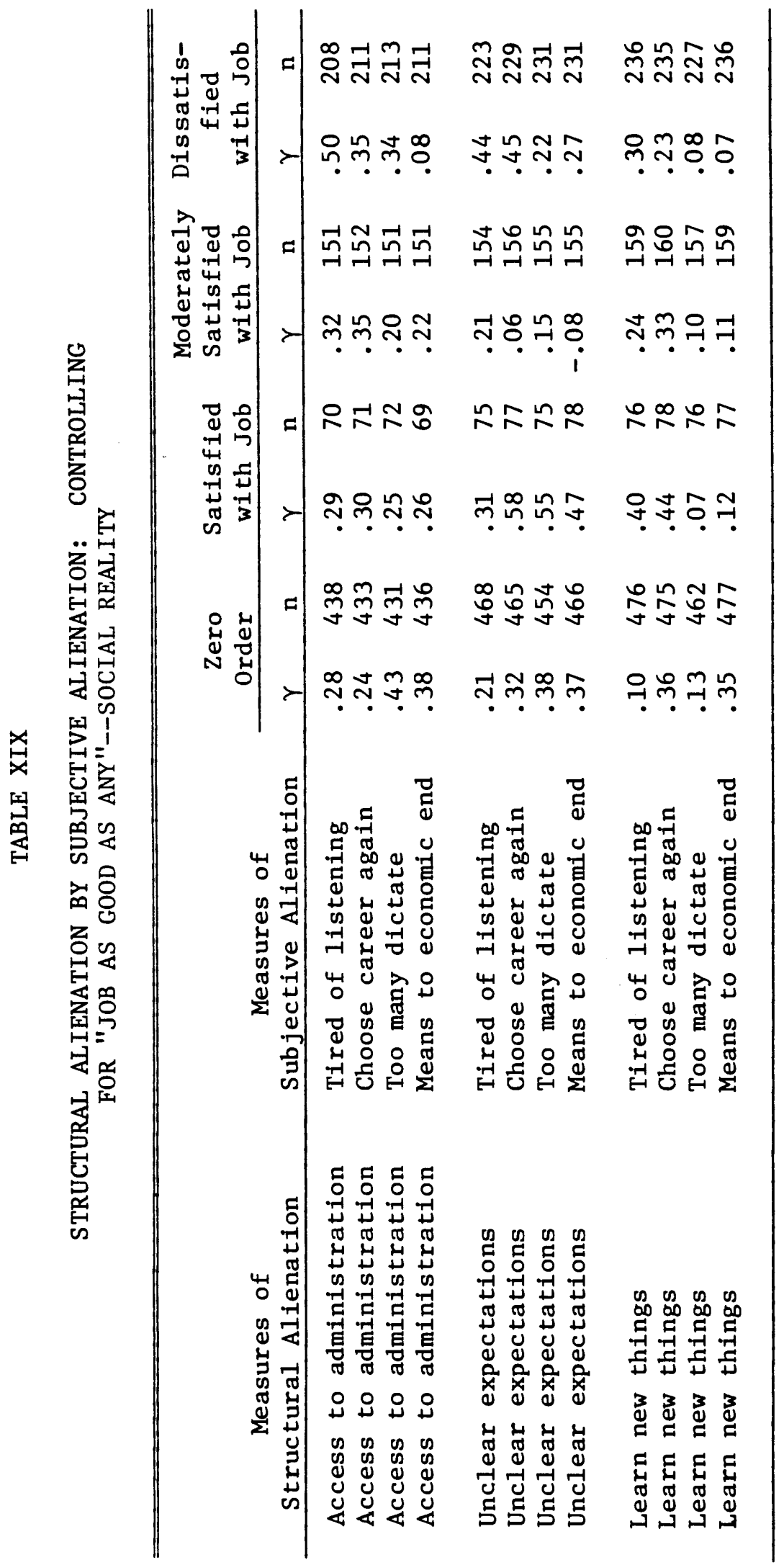


salary and are moderately satisfied with their job. It appears that the respondents in this group tend to be equally concerned about structural and social "reality" issues.

\section{POSITIVE SOCIAL REALITY}

Seventeen of the forty-eight ( 47 percent) of the partial gammas decrease by more than 5 percent for the respondents who agree that they have an adequate opportunity for advancement and who are satisfied with their job and salary.

Overall, the data from Tables XVII-XIX suggest that for the respondents in each of the three categories the social "reality" issues do play an important role in depressing the conscious expression of alienation. Very interestingly, the percentage of decreased gammas is uniform for the respondents in the three categories.

\section{SOCIETAL ALIENATION AND SOCIAL REALITY}

Tables XX-XXII illustrate the zero-order and secondorder gammas for the societal by subjective alienation and controlling for social "reality."

Among the respondents who agree that they have little opportunity for advancement, have an unsatisfactory salary, and who are dissatisfied with their job, the partial gammas decrease by 5 percent or more in 27 percent of the partial gammas. Having little opportunity for advancement on the 


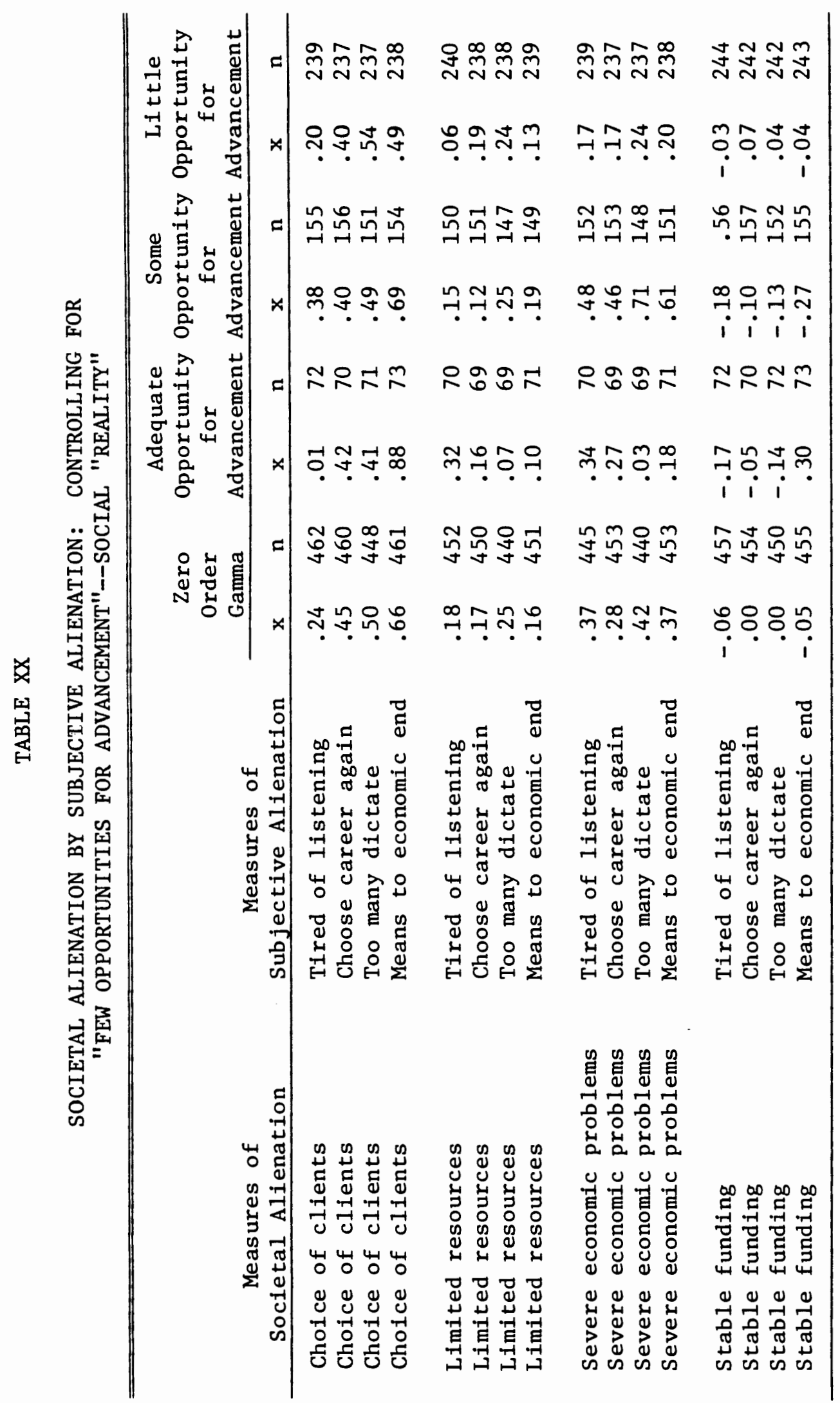




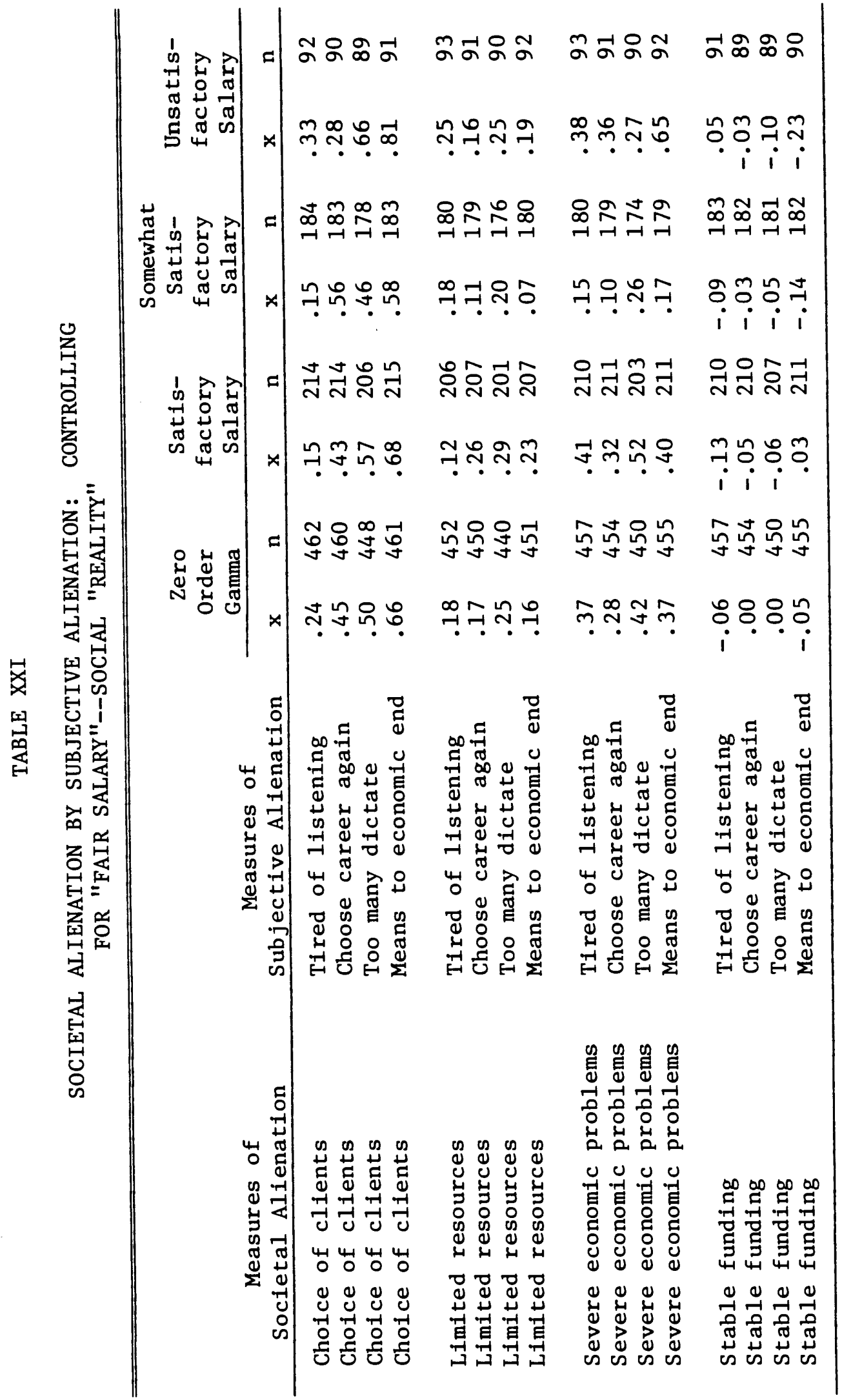




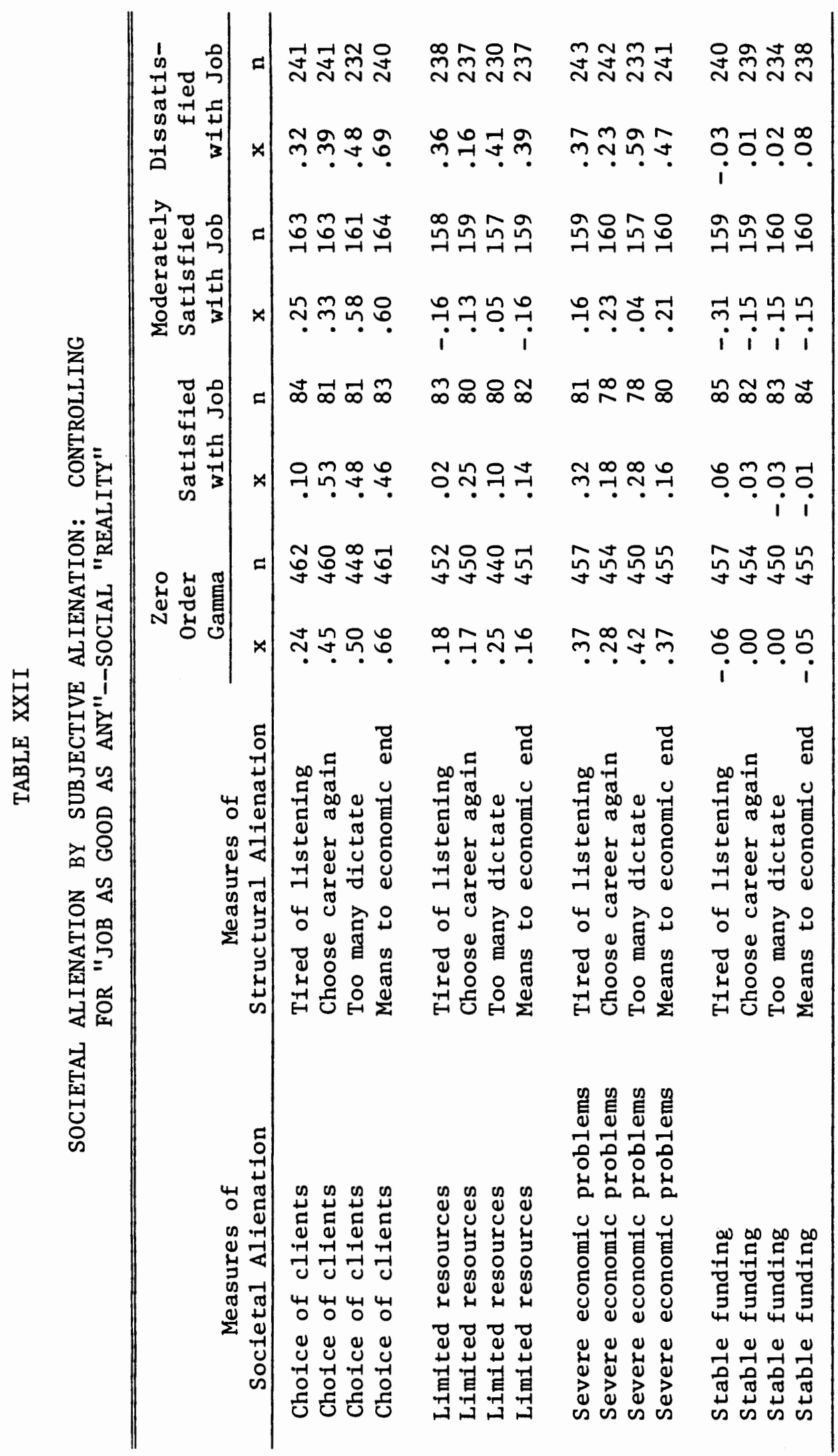


job appears to have the strongest influence in mediating the relationship between societal issues and the conscious expression of alienation.

An overwhelming 63 percent of the partial gammas decrease for the respondents who agree somewhat they they are able to advance on the job and that their salary and job are satisfactory. "Fair salary" and "job as good as any" are the two social reality issues that have the strongest influence in explaining why the respondents in our study tend to resist expressing more feelings of burnout and alienation from their work.

For the respondents who are basically agreed that they have opportunity for advancement on the job and who are generally satisfied with their salary and their job, the second-order gammas decrease 48 percent. Two of the three variables have a moderate influence on the zero-order correlation. The exception is "fair salary," which shows that the second-order gammas only decrease in five out of sixteen relationships. Hence, having a relatively fair salary does not explain why the respondents in this category did not express their feelings of alienation.

Overall, the data in Tables XX-XXII suggest that the social reality issues do influence the relationship between societal alienation and subjective alienation for respondents in the first two categories. They play a less influential role for the respondents who disagree that their job 
provides opportunity for advancement and that their salary and job are satisfactory. For these respondents, other types of issues appear to influence the resistance of these respondents to expressing their conscious feelings about their dissatisfaction and/or alienation from work.

\section{SUMMARY}

In conclusion, our findings do support our hypothesis that the social "reality" variables will change the relationship between the independent and dependent variables. They provide at least a moderately strong explanation of why there appears to be more structural/societal alienation than the conscious psychological expression of feelings of alienation from work. We recognize that there may be a number of reasons other than social reality that may account for this phenomenon; however, our findings support the Marxian concepts of "false consciousness" and the role of the "historical moment" in an individual's perceptions of his/her work.

Marx conceptualizes work alienation as the breakdown of the "natural interconnectedness of species-being" (Ritzer, 1981, p. 44). That is, according to Marx, the objective conditions or the:

- macro-objective structures of capitalism are involved in this breakdown--the market, money, commodities, capital, and, most importantiy, the division of labor and the resulting class system.

(Ritzer, 1981, p. 61) 
For these reasons, we chose to examine whether social "reality" issues such as having opportunity to advance on the job, having a fair salary, and considering that one's job may be as good as one can expect in an industrial society may suppress feelings of alienation. Finifter describe: Marx's concept of "false consciousness" as well as our conceptualization of social "reality" as follows:

Presumably, many have been socialized to expect no more than they have actually received; therefore, felt content and did not subjectively experience dissatisfaction or alienation. (1972, p. 6)

Therefore, we contend that social service workers are "products" of a society that places value on competition, economic advancement, egotistic ends, and detachment from other human beings. Social service workers may not be unlike other people in society in that they have been socialized to adapt to the alienating conditions in society. Perhaps the "alienating processes are either so effective, or have been going on continuously for such a long period, that one no longer experiences them on a cognitive level" (Israel, 1971, p. 80).

It is for the above reasons that we, unlike many of the empirical studies on work alienation in the United States, chose to examine how the structure of the work place and the structure of society contribute to the conscious expression of alienation. And our findings do support and are in keeping with the Marxian paradigm. With 
Kohn (1976), we have begun to demonstrate that the objective and subjective aspects of alienation can be integrated. 


\section{CHAPTER VII}

\section{DISCUSSION}

\section{INTRODUCTION}

It is . . almost as difficult to measure... feelings of discontent about work as it is to measure other basic feelings such as pride, love, or hate. Most of the leading experts on work in America have expressed disappointment over the unsophisticated techniques commonly used to measure work dissatisfaction. (Work in America, 1973, p. 14)

There are few studies that consider the relationship between feelings of discontent or subjective alienation of workers and the structural conditions of the work place. To our knowledge, our study is the first to examine, in the context of the social services, both structural and societal conditions and their relationship to subjective alienation.

\section{CONCLUSIONS}

Throughout this study, we have attempted, using a Marxian analysis, to distinguish between the experience and expression of alienation, and the structural and societal conditions contributing to it.

Toward this end, we employed survey research methods to analyze the relationships between these three types of alienation. Our research supports our three hypotheses: 
first, that there is a strong relationship between societal/ structural alienation and subjective alienation; second, that societal/structural alienation is clearly more apparent in our sample than is subjective alienation; and finally, that social reality significantly influences the relationships between these types of alienation. Even with high levels of structural/societal alienation, less subjective alienation can be measured due in part to social reality factors.

That structural alienation is more evident than subjective alienation is an intriguing finding. If the structural conditions of work are so confining as to be alienating, then why do respondents not reveal a corresponding level of subjective alienation? The answers are complex and varied. The structural conditions of work (i.e., amount of paper work, autonomy, access to administration) are to a great extent mediated by the conditions of society at large (social reality) and so too the responses to that structure. Obviously other factors, other than those we designated as social reality, mediate this relationship. We can guess that variables such as education, length of time in the job, and gender could have impact. We believe that further research is necessary to examine the effect of variables such as these upon the individual's expression of alienation. Another important factor in the expression of alienation is the way(s) it can be alleviated or managed. It is quite 
possible that without creative personal intervention, such as sports, nonwork-related activities, and a variety of stress reduction techniques, social service workers would experience alienation in direct proportion to the existence of alienating structural conditions. We are critical of workshops and other individual means as the only ways of reducing burnout; these methods only assuage the symptom without treating the cause. While we in no way advocate the elimination of these solutions, we would hope that the reader, as well as the social service workers concerned, would see these solutions as a beginning point from which to change the structure. Our research has led us to believe that burnout and alienation will always exist unless the conditions of work are changed. Social work as a profession suffers its alienating effects from two sides: (1) it is like any other work, given to inherently alienating characteristics, and (2) it exists within a fissure of contradictory societal and political values.

As seen in Table IV, more than half of the respondents stated that the structural aspects of work which Marx theorized were alienating, were descriptive of their jobs in social work. That such a large number of people report that these conditions exist to a moderate or high degree suggests that Braverman's ideas that white-collar jobs can no longer be completely distinguishable from blue-collar jobs, are applicable to work in the social services. While over half 
are reporting that structurally alienating conditions of work are descriptive of their jobs, this consistency is not seen in respondents' apparent subjective alienation (see Table VI). The efficacy of Marx's notion of false consciousness is borne out.

The specific work conditions which determine an alienating environment, such as paper work or any other condition which requires attention to the mere mechanics of work or which is in and of itself meaningless, greatly reduces a worker's ability to be professionally effective. Our data show that these conditions do result in detachment from clients, co-workers, and ultimately from social work:

But a growing number of white-collar jobs have much in common with the jobs of auto workers and steel workers. Indeed, discontent with the intrinsic factors of work has spread even to those with management status. (Work in America, 1973, p. 14)

If social work is beginning to take the form of assembly line production, then it becomes simpler to comprehend how far removed workers can become in their professional goals of directly helping to serve the needs of their clients. Those respondents who are describing the conditions of their jobs as being alienating, are also those respondents who would not again choose to become social workers. The gravity of this fact cannot be overemphasized. If social work is to remain viable, and its goal of social change intact, then clearly the structure of the work place must change. If social workers are inhibited by bureaucratic 
necessities, then ultimately their clients will suffer and the social order will continue in its dangerously haphazard and condemning fashion. Social workers who burn out and leave the profession may also leave the commitment to changing social and political conditions. The current trend in social work toward the attainment of legitimate professional status (through licensing) seems to ignore the basic problems evident in our findings. We would not be in opposition to this trend if it were to incorporate the fact that a majority of social workers are not in private practice, and therefore lack control over the product of their work.

While the granting of status is in and of itself an issue, it is important that social workers, in order to perhaps more effectively do their jobs, be given such legitimacy. However, this does not really resolve the matter of altering the structure of the work place. Blue-collar America has looked in the past to unions to do battle for better work conditions. Neo-Marxist social critics tell us, however, that unions have only bettered the work conditions within the factory in order to maintain the worker in his menial position. Even if one were to give unions the benefit of the doubt, and work conditions within the social services were altered, one still has not resolved the larger issues which caused the alienating conditions in the first place. The conditions of work, any work, reflect the conditions of society at large. In our study, we learned that 
merely changing the technology of the work place does not eliminate the problem of alienation from work because the "root causes stem largely from contradictions located within the structure of American society" (Brager \& Halloway, 1978, pp. 17-18).

The profession of social work and social service workers have historically functioned in a precarious position vis-à-vis the basic values of Western society, specifically the operant values of present-day post-industrial America. The high frequency of societal alienation among our respondents lends great credence to the perspective of social work as existing in direct conflict and contradiction with a capitalistic system.

Capitalism is based upon the premise that each individual is free to compete with skills and/or goods in a free market, and that each has available to him/her an equal opportunity to succeed.

Since modern man experiences himself both as the seller and as the commodity to be sold on the market, his self-esteem depends on conditions beyond his control. If he is successful, he is valuable; if he is not, he is worthless. (Fromm, 1971; from Work in America, 1973, p. 5)

In a pure free market economy, the whole concept of social work must be a priori foreign. The Protestant work ethic has been tempered in double-bind fashion by the notion of the Christian work ethic. It is fine to help a neighbor in need, but it is not fine to support those for whom capitalism has failed. Capitalism does not provide for those who 
could never compete in the first place, nor does it willingly provide when its mechanisms cease to function.

To review, there is a strong association between the societal and structural conditions and social service workers' experience of alienation. Our hypothesis that workers would express less alienation than their report of alienating structural conditions would indicate, proves to be true. Social reality factors, our attempt to operationalize Marx's concept of false consciousness, do account for this difference.

We are concerned that movement toward social change not overlook the seemingly mundane: the conditions under which Americans work, and the work itself, are truly at the heart of the matter. Nor should those focusing on changing work conditions ignore social work's goal of creating a more egalitarian society.

We do not believe that burnout and alienation will vanish in the near future. Given the current economic and political climate, it is likely that burnout will become an even larger problem. While the need for social services is increasing, hostility surrounding their provision is increasing as well. 
BIBL IOGRAPHY 
Aiken, M. and Hage, J. "Organizational Alienation: A Comparative Analysis." American Sociological Review 31 (August 1966):497-507.

Anderson, Charles A. and Gibson, Jeffrey R. Toward a New Sociology. Homewood, Illinois: Dorsey Press, 1978.

Archibald, Peter W. "Using Marx's Theory of Alienation Empirically." In Theories of Alienation. Edited by Felix Geyer and David R. Schweitzer. Leiden: H. E. Stenfert Kroese, 1976.

Baker, Mary R. "Social Work: A Profession or a Service Delivery System?" Social Casework 55 (June 1974): $381-384$.

Billingsley, Andrew. "Bureaucratic and Professional Orientation Patterns in Casework." Social Service Review $38: 4(1964): 400-407$.

Blankenship, R. "Organizational Careers: An Interactionist Perspective." Sociological Quarterly 14:1 (Winter 1973) : 88-98.

Blauner, Robert. Alienation and Freedom: The Factory Worker and His Industry. Chicago: University of Chicago Press, 1964.

Bonjean, Charles M. and Grimes, Michael D. "Bureaucracy and Alienation: A Dimensional Approach." Social Forces 48(3):365-373.

Brager, George and Halloway, Stephen. Changing Human Service Organizations. New York: The Free Press, 1978.

Braverman, Harry. Labor and Monopoly Capital. New York: Monthly Review Press, 1974.

Browning, Charles J., Farmer, Malcolm F., Kirk, David H. and Mitchen, Duncan G. "On the Meaning of Alienation." American Sociological Review 26:5 (1961):780-781.

Clark, John P. "Measuring Alienation within a Social System." American Sociological Review 24 (December

1959) : 849-852. 
Cloward, Richard A. and Piven, Frances Fox. Radical Social Work. Edited by Roy Baily and Mike Brake. New York: Random House, 1975.

Corrigan, Paul and Leonard, Peter. Social Work Practice under Capitalism: A Marxist Approach. McMillan Press, 1979.

Dahrendorf, Ralf. Class and Class Conflict in Industrial Society. Palo Alto: Stanford University Press, 1959 .

Daley, Michael R. "Burnout: Smoldering Problem in Protective Services." Social Work 24 (September 1979): 375-379.

Daniels, Arlene Kaplan. "How Free Should Professionals Be?" In The Professions and Their Prospects, pp. 39-57. Edited by Eliot Friedson. Beverly Hills : Sage Publications, 1973.

Dean, Dwight G. "Alienation and Political Apathy." Social Force 38:3 (March 1960):185-195.

Edelwich, Jerry and Brodsky, Archie. Burn-Out: Stages of Disillusionment in the Helping Professions. New York: Human Sciences Press, 1980.

Epstein, I. and Conrad, K. "The Empirical Limits of Social Work Professionalism." In The Management of Human Services. Edited by R. Sarri and Y. Hasenfield. Columbia, 1968.

Fever, L. "What Is Alienation." New Politics 1 (Spring 1962).

Finch, Wilbur A. "Social Workers versus Bureaucracy." Social Work 21:5 (1976):370-375.

Finifter, Ada W. Alienation and the Social System. New York: John Wiley \& Sons, Inc., 1972.

Freidson, Eliot, ed. "Professions and the Occupational Principle." In The Professions and Their Prospects, pp. 19-38. Beverly Hills: Sage Publications, 1973.

Freudenberger, Herbert J. "Burn-Out: Occupational Hazard of the Child Care Worker." Child Care Quarterly $6(2): 90-99$. 
Freudenberger, Herbert J. "How to Survive." Nations Business (December 1980):53-56. "The Staff Burn-Out Syndrome in Alternative In-
titutions." Psychotherapy: Theory, Research, and Practice, 12:1 (1975):73-82.

Fromm, Erich. The Revolution of Hope. New York: Bantam Books, 1971 .

Fry, L. and Miller, J. "Observations on an Emergency Profession." Journal of Sociology and Social Welfare 4:5 (May 1977).

Galper, Jeffery H. The Politics of Social Services. New Jersey: Prentice Hall, 1975.

Garther, Alan. The Preparation of Human Service Professionals. New York: Human Science Press, 1976.

Geyer, Felix and Schweitzer, David R. Theories of Alienation: Critical Perspectives in Philosophy and the Social Sciences. Leiden: H. E. Stenfert Kroese, 1976.

Goffman, E. Asylums: Essays on the Social Situation of Mental Patients and Other Inmates. Garden City, New York: Doubleday, 1961.

Goldthorpe, J. H. "Attitudes and Behaviors of Car Assembly Workers: A Deviant Case and a Theoretical Critique." The British Journal of Sociology XVIII (1966): 227-244.

Green, A. D. "The Professional Worker in the Bureaucracy." Social Service Review 40 (March 1966).

Greenwood, Ernst. "Attributes of a Profession." Social Work 2 (Juiy 1957):44-55.

Hackman, J. R. and Lawler, E. E. "Employees Reactions to Job Characteristics." Journal of Applied Psychology 55 (3) (1971):259-286.

Hall, Richard H. Occupations and the Social Structure. New Jersey: Prentice Hall, 1969.

"Professionalization and Bureaucratization." American Sociological Review 33 (February 1968): 92-104. 
Harrison, W. David. "Role Strain and Burnout in Child Protective Service Workers." Social Service Review $54: 1$ (1980):31-44.

Haenfeld, Yeheskel and English, Richard A. Human Service Organizations: A Book of Readings. Ann Arbor: The University of Michigan Press, 1974.

Haug, M. "Professionalization and Unionism: A Jurisdictional Dispute." American Behavioral Scientist 14 (1971) :525-540. 8 (1975).

"The Deprofession of Everyone?" Social Focus and Sussman, M. "Professionalization and the PubIic." Sociological Inquiry 39 (Winter 1969):57-64.

Heunks, F. J. "Vervreemding onderzocht" (Alienation Investigated). Mens En Maatshappij 52:2 (1977):172-205.

Hobart, C. W. "Types of Alienation: Etiology and Interrelationships." Canadian Review of Sociology and Anthropology 2:2 (May 1965):92-116.

Horton, J. "The Dehumanization of Anomie and Alienation: A Problem in the Ideology of Sociology." British Journal of Sociology $15: 4$ (December 1964): 283-300.

Howe, Elizabeth. "Public Professions and the Private Model of Professionalism." Social Work 25 (May 1980): 179-191.

Hyja, Jan. "Causes of Alienation." Portland State University Sociology Department, n.d.

Israel, Joachim. Alienation: From Marx to Modern Sociology. Boston: Allyn and Bacon, Inc., 1971.

Kadushin, A. "Prestige of Social Work--Facts and Factors." Social Work 3 (April 1958):37-43.

Kohn, Melvin L. "Occupational Structure and Alienation." American Journal of Sociology 82:1 (1976):111-130.

Larson, Magali Sarfatti. The Rise of Professionalism: A Sociological Analysis. Los Angeles: University of California Press, 1977. 
Lawler, Edward J. and Hage, Jerald. "Professional Bureaucratic Conflict and Intraorganizational Powerlessness among Social Workers." Journal of Sociology and Social Welfare 1 (1973):172-193.

Lawton, Henry W. and Magarelli, Anthony. "Stress among Public Child Welfare Workers." Catalyst 7 (1980): 57-65.

Leighninger, L. and Knickmeyer, R. "The Rank and File Movement: The Relevance of Radical Social Work Traditions to Modern Social Work Practice." Journal of Sociology and Social Welfare $4: 3$ (1977):166-177.

Ludz, Peter C. "Alienation as a Concept in the Social Sciences." In Theories of Alienation. Edited by Felix Geyer and DavidR. Schweitzer. Leiden: H. E. Stenfert Kroese, 1976.

Lystad, M. H. "Social Alienation: A Review of Current Literature." Sociological Quarterly 13 (Winter 1972): 90-113.

Marx, Karl. Economic and Philosophical Manuscripts. 1844. and Engels, Friedrich. "On Alienation." In Images of Man. Edited by C. Wright Mills. New York: George Braziller Inc., 1960.

Maslach, Christina. "Burned-Out." Human Behavior 3 (1976): $16-22$.

"Characteristics of Staff Burnout in Mental Health Settings." Hospital and Community Psychiatry $29: 1$ (Apri1 1978): 233-237.

Meinart, R. "Profession Satisfaction of Social Workers." Social Work 20 (1975):64-65.

Mende1, Werner W. "Staff Burn-out: Diagnosis, Treatment and Prevention." New Directions for Mental Health Services 2 (1979): $75-83$.

Merton, Robert K. "Social Theory and Social Structure. In Theory of Deviance, pp. 73-105. Edited by Traub and Little. Peacock, 1975.

Meszaros, I. Marx's Theory of Alienation. Harper Torchbook, 1972 . 
Miller, George A. "Professionals in Bureaucracy: Alienation among Industrial Scientists and Engineers." In Alienation and the Social System. Edited by Ada W. Finifter. New York: John Wiley and Son, Inc., 1972.

Millis, C. "Turnover among Childcare Workers." New York University, 1979.

Minahan, Anne. "Burnout and Organizational Change." Social Work $25: 2(1980): 87$.

Morrissey, Elizabeth and Gillispie, David. "Technology and the Conflict of Professionals in Bureaucratic Organizations." The Sociological Quarterly 16 (1975): 319-333.

Muldoon, John F. "The Burnout Syndrome: Caring for Yourself." Visual Impairment and Blindness 74:4 (1980): 112-116.

Murdia, Ratina. "Task-Structure and Work Alienation in Human Service Organizations." The Indian Journal of Social Work XI: 2 (1979):165-175.

Naik, Neena. "Study of Alienation amongst Bank Employees." The Indian Journal of Social Work $39: 3$ (October 1978):247-257.

Neal, Arthur G. and Groat, Theodore. "Social Class Correlates of Stability and Change in Levels of Alienation: A Longitudinal Study." Sociological Quarterly 15 (1974): 548-558.

Neal, Arthur G. and Rettig, Solomon. "Dimensions of Alienation among Manual and Non-manual Workers." American Sociological Review 28 (August 1963):599-608.

Neal, Arthur G. and Seeman, Melvin. "Organizations and Powerlessness: A Test of the Mediating Hypothesis." American Sociological Review 29 (1964):216-226.

Nelson, J. "Anomie: Comparisons between the 01d and New Middle Class." American Journal of Sociology 74:2 (September 1968):184-192.

Nettler, Gwynn. "A Measure of Alienation." American Sociological Review 22 (December 1952).

Nicholson, N., Wall, T. and Lischeron, Jr. "The Predictability of Absence and Propensity to Leave from Employees Job Satisfaction and Attitudes toward Influence in Decision-making." Human Relations 30 (1977). 
Ott, Lyman, Mendenhall, William and Larson, Richard F. Statistics: A Tool for the Social Sciences. North Scituate: Duxburn Press, second edition, 1978.

Ozawa, Martha N. "Development of Social Services in Industry: Why and How?" Social Work 25:6 (1980):464-475.

Pearlin, L. "Alienation from Work: A Study of Nursing Personnel." American Sociological Review 27 (1962).

Pines, Ayala and Maslach, Christina. "Characteristics of Staff Burnout in Mental Health Settings." Hospital and Community Psychiatry 29:4 (April 1978): $233-237$.

Pilisuk, M. "The Future of Human Services without Funding." American Journal of Orthopsychiatry $50: 2$ (April 1980).

Piven, A. and Kafry, D. "Occupation Tedium of Social Service Professionals." Social Work 23:2 (1978):499507.

Podheretz, N. "Where Is the Beat Genration Going?" Esquire (December 1958).

Pruger, Robert. "The Good Bureaucrat." Social Work 18 (1973): 26-32.

Reisman, D. The Lonely Crowd. New Haven: Yale University Press, 1950 .

Resnick, Herman and Rino, Patti J. Change from Within: Humanizing Social Welfare Organizations. Philadelphia: Temple University Press, 1980.

Rinder, I. and Campbel1, D. "Varieties of Inauthenticity." Phylon 13:4 (1952):270-275.

Ritzer, George. "Professionalism and the Individual." In The Professions and Their Prospects, pp. 59-73. Edited by Eliot Freidson. Beverly Hills: Sage Publications, 1973.

Toward an Integrated Sociological Paradigm. Allyn and Bacon, 1981.

Ruzek, Sheryl K. "Making Social Work Accountable." In The Professions and Their Prospects, pp. 217-243. Edited by Eliot Freidson. Beverly Hilis: Sage Publications, 1973.

Sartre, J. Anti-Semite and Jew. New York: Grove Press, 1966 . 
Schacht, Richard. Alienation. New York: Anchor, 1971.

Schaff, Adan. Marxism and the Human Individual. McGrawHill, 1970 .

Scheler, Max. "Social Structure and Anomie." In Theories of Deviance, p. 93. Edited by Traub and Little. Peacock, 1975 .

Schroyer, T. The Critique of Domination. Beacon, 1975.

Seeman, Melvin. "Alienation Studies." Annual Review of Sociology 1 (1975): 91-123.

"Empirical Alienation Studies: An Overview." In Theories of Alienation. Edited by Felix Geyer and David Schweitzer. Leiden: H. E. Stenfert Kroese, 1976 .

"On the Meaning of Alienation." American SocioIogical Review 24 (1959):783-791.

"On the Personal Consequences of Alienation in Work." American Sociological Review 32:2 (1967): 273-285.

"Status and Identity: The Problem of Inauthenticity." Pacific Sociological Review $9: 2$ (Fall 1966) :67-73.

Selltiz, Claire, Wrightsman, Lawrence S and Cook, Stuart W. Research Methods in Social Relations. San Francisco: Holt, Rinehart and Winston, third edition, 1976 .

Shannon, Coleen and Saleebey, Dennis. "Training Child Welfare Workers to Cope with Burnout." Child Welfare 59 (September/October 1980):463-468.

Shepard, J. "Alienation as a Process: Work as a Case in Point." Sociological Quarterly 13 (Spring 1972): 161-173.

Snizek, W. E. "Halls' Professionalism Scale: An Empirical Reassessment." American Sociological Review 37 (1972): 109-114.

Specht, Harry. "The Deprofessionalization of Social Work." Social Work 17 (March 1972):13-15. 
Strauss, G. "Some Notes of Power Equalization." In The Social Science of Organizations. Edited by $\mathrm{H}$. Leavitt. New York: Prentice Hall, 1963.

Thomson, Susan G. "An Investigation of the Proletarianization of Labor Using Survey Data." Tuskegee Institute, Jlasbora State College, New Jersey, 1979.

Tudor, Bill. "A Specification of Relationships between Job Complexity and Powerlessness." American Sociological Review 37 (1972):596-604.

Wagner, David and Cohen, Marcia B. "Social Workers, Class, and Professionalism." Catalyst 1:25 (1978):56.

Walker, Samuel. "Police Professionalism: Another Look at the Issues." Journal of Sociology and Social Welfare 3 (July 1976) :701-711.

Wasserman, Harry. "The Professional Social Worker in a Bureaucracy." Social Work 16 (1971):89-95.

Wenocur, Stanley and Sherman, Wendy. "Empowering the Social Worker." March 1980. (Mimeograph.)

Whatcott, Weston E. "Bureaucratic Focus and Service Delivery." Social Work 19 (July 1974):432-437.

Weed, Roger 0. "Burnout Syndrome." Paper Presented at the AAMD Conference, Miami, Florida, May 1979.

Wilensky, Harold. "The Professionalization of Everyone?" American Journal of Sociology 70 (1964):137-158.

Work in America: Report of a Special Task Force to the Secretary of Health, Education and Welfare. Cambridge: MIT Press, 1973.

Zurcher, Louis A., Jr., Meadow, Arnold and Zurcher, Susan Lee. "Value Orientation, Role Conflict, and Alienation from Work: A Cross-Cultural Study." American Sociological Review 39 (August 1965):539-548. 
APPENDIX 


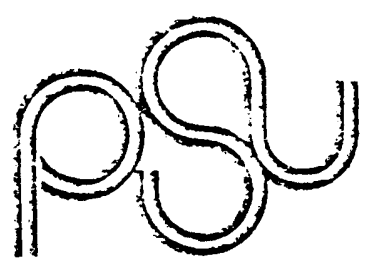

ITITLAND

STATE

VERSITY

box 751

:orecun

97207

229.4712

To whom it may concern,

This student is representing a small group of Social Work graduate students engaged in a thesis project concerning various aspects of woring in social services. At this point they are interested in baking contact with social workers who are not members of NASW; social service workers without advanced degrees; and workers with 1ess than a bachelor's degree. They are particularly concerned with investigating how positions are organized, how workers view thenselves and their positions, and how they expect their rareers to evolve.

They would greatly appreciate your cooperation in helping trem obtain rames and addresses of workers who fit the categories they are interested in so that they may interview or send questionnaires to them. Please be assured that full confidentiality about the agency and the stafi will be maintained.

Thank you very much for your help.

Sincerely,

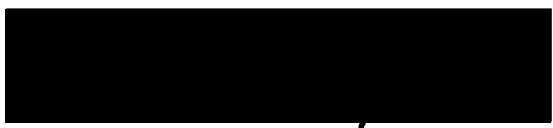

John F. Longres, Ph.D.

Advisor to the Research Project 

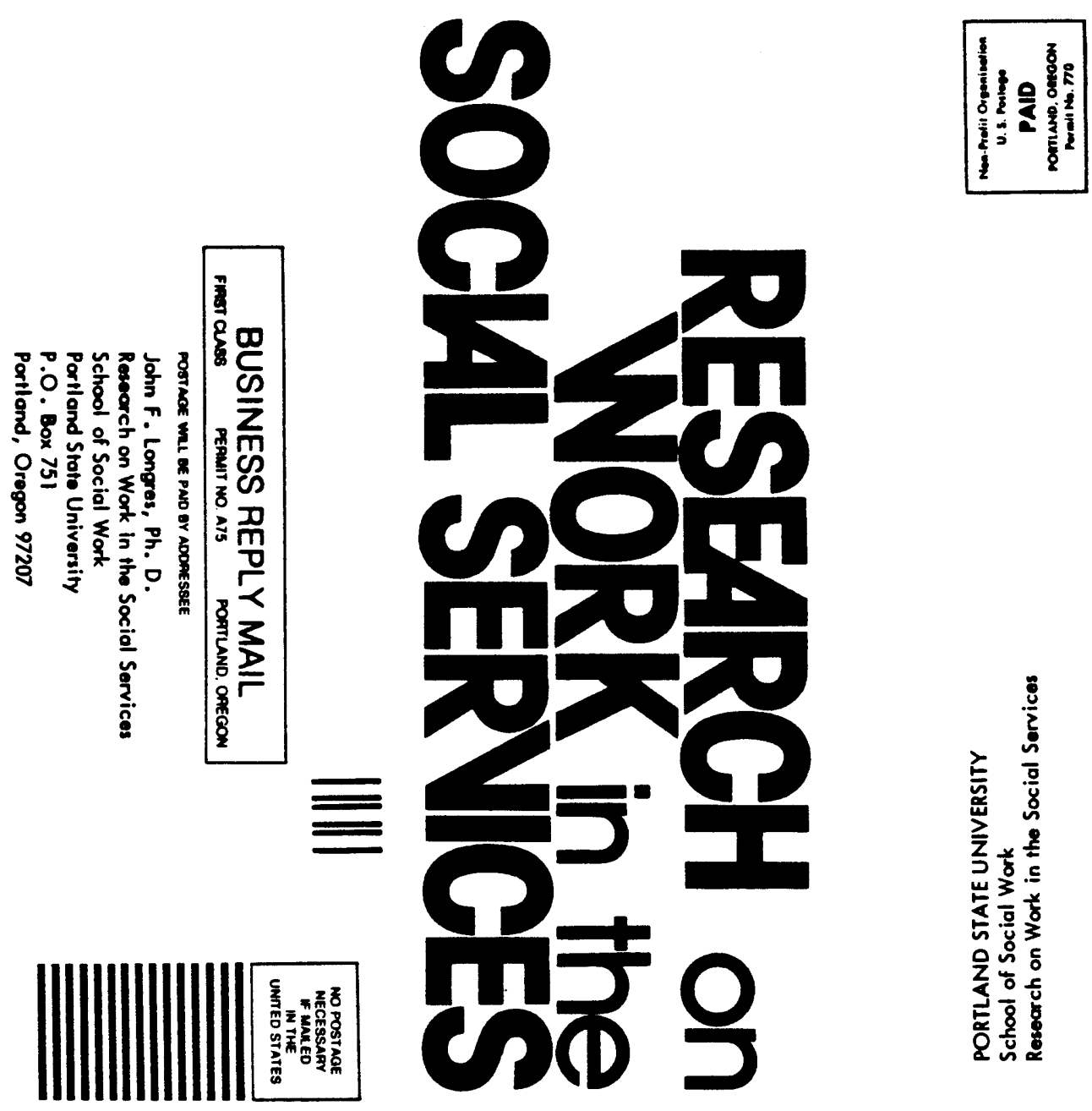

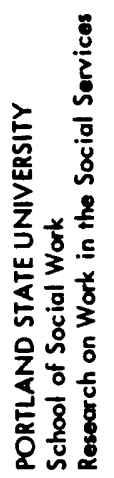

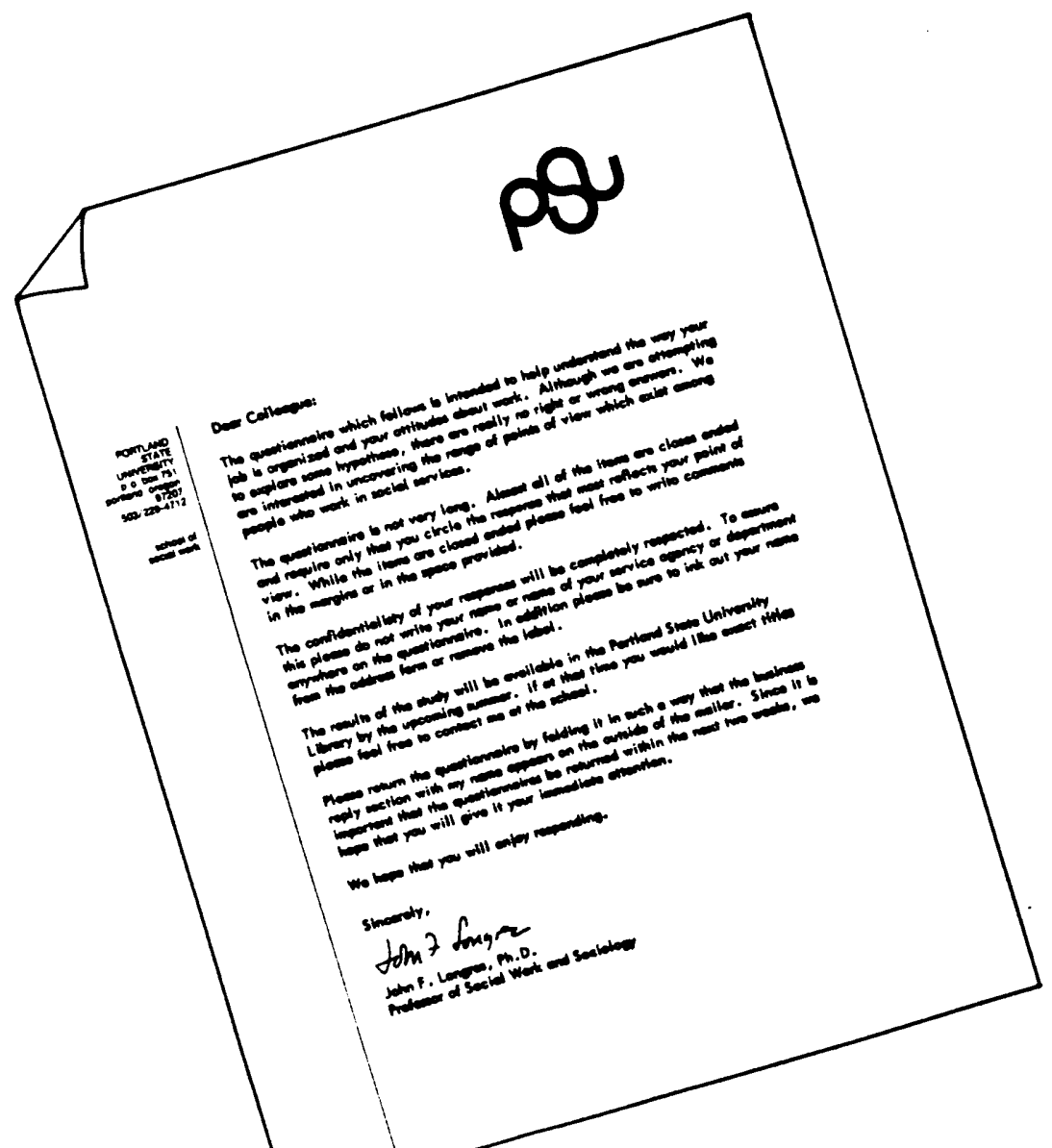

GENERAL INFORMATION

SEX: Male Femole

Plean indicote your AGE at leat birthdoy.

Plece indicote the yecrs of FORMAL EDUCATION complated and or hichent degree corned.

Are you a member of ary PROFESSIONAL ASSOCIATIONS?

Yo No

If yes, pleces indicote which.

Are you ACSW (Academy of Cortified Social Workers)? Yes No

Are you a member of a UNION?

Yes No

Do you mork for a social envice AGENCY or DEPATMENT?

If res, plecen onswer the following:

the service is privote

I work port tim

full time

my job title is

my chief duties are in cenorortcouraling eupervision odministration other

my deties also include (chock all thet oppiy) conomort couneling upervision odministrotion other

Do you hove o PRIVATE PRACTICE?
If yes,
full time port time 


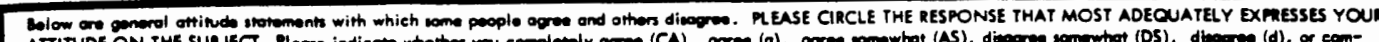

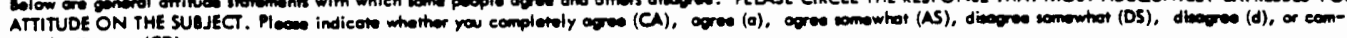
plewely diboon $(C D)$.

I on on idealist.

I don't like to think of mpeif on pere of a protemionol clem of people.

ca as os a CD

CA a AS OS CO

I think it is wise to do thing in the expected moy.

CA AS DS a CD

My own neade muat come bafors thowe of othen. CA AS DS d CD

Mony times I feel that I heve littile influence over the thinge that heppen to me.

I how o les of imomen beriden my mork ond cares.

I find I'm protty reolistic about thinger.

Mant of us ore the victim of forcen we cen mither understend or control.

I wish people showed greorer rempect for ma a a profecuionol perion.

\section{CA. AS DS a CO}

CA a AS OS a CO

Ca. AS OS a CO

CA a AS DS A CD
CA AS OS d CD
I dialike people who al woy follow the unal cociol comrention.

The wall baing of the group is as importent as my own.

ca as os a CD

CA a AS OS A CD

It is impossible for ma to believe thot chence or luck plon an impertent role in my life.

I cen't find time to do thing that rolex ma.

It bothers me to think that 1 an not corsidured port of a real protimation.

In the and we cen only loak out for ourmilves.

Dy ring on octive part, people con comrol the wociety in which they live.

It doen't bother we when thing ore uncertoin and unpredicteble.
CA AS DS a CO

ca. As os a co

CA as OS a CD

ca as OS a CO

Ca. as de a CO

CA AS OS d CO

The following ore phrom that deceribe the conditione under which people work. CIRCLE THE RESPONSE THAT MOST OAJECTIVELY DEGRIBES THE CONDITIONS UNDE WHICH YOU PRESENTIY ARE WORKING.

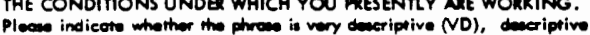
Pleces indicote whecther the phrese is very deceriptive (ND), decoriptive (d) romewhat deveriptive (SD), womentor not deveriptive (SND), not descriptive (nd), a very non-deceriptive (VNO). For respondents who do not work in a social serviea oponey or doportment, of for thow who do not work dirsectly with sociol service clionts, some of the itement mon not apply. If this is the cas plecen eirele not-applicable (NA).

\begin{abstract}
VD d SD SND a VND require prest mental effort NA
\end{abstract} VD \& SD SND nd VND eceen to odministrotors NA

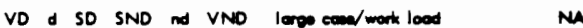
VD \& SD SND nd VND pepon work NA VD d SD SND nd VND requinem o high level of skill NA VD d SO SND nd VND unclea expectations from others NA VD \& SO SND nd VND participation in poliey/fropom NA devolopmem

VD SO SND a VND cloce upervision NA

VD a SD SND nd VND flexible rvies and procendures Na

VD d SD SND nd VND mast work reng fout

VD d SD SND nd VND frequent policy/progeren chengen $N A$

VD d SD SNO nd VND comfortable ewes in which to work NA

VO d SD SND nd VND nam NA

VO a SO SND nd VND lean new thingerery doy

VO A SD SND nd VND choice of elienw/people to

VD d SO SND nd VND omistonce from eommorken or NA

anociots

VD d SD SND nd VND routime work

Na

VD d SD SND nd VND time enounh to do expected mork NM

VD d SD SND nd VNO mall number of persomel

VO SO SND nd VNO

VD SD SND nd VND

VD SO SND nd VND

VD $d$ SD SND nd VND

VD $d$ SD SND nd VND

VO SO SND nd VND

VD SO SNO nd VND

VO S SO SNO nd VNO

VD SD SNO nd VND

VD \& SD SND nd VND

VO d SD SNO n VNO

VO d SO SNO n VNO

Vo d SO SNO YNO

VO d SD SND W VND

VD \& SD SNO nd VNO etion whon will inety

comemenity wppont

low community store

- rula maneal or beed

fair wolory or poy

no writhen jab deneription

jab mobility

chermole of communication pocified

union of morken acocietion

NA

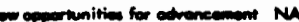

competiotion for el elem

M

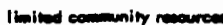

Na

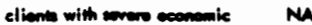
preblem

able holing

NA

Na

Na

Na

Na

M

M formol and impornonel

Below an rom wotement obout work which some people agoe and orthen disogree. PLEASE CIRCLE THE REPPONSE THAT BEST OESCRIBES YOUR ATTITUDE ABOUT YOUR WORK. Pleces indicoto whather you completely ares (CA), agree (o),

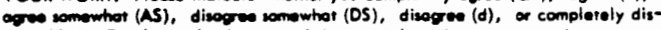
aren(CD). For thow who do not wort in a social envice ageney or depar iment come of the stotements may not apply, if this is the can plecen circle not applicable (NA).

My job is probebly a good a any ovailable

rom.

CA - AS OS a CD NA

I feel I am positively influencing other people's lives in my work.

I hove greot respect for my ed lespes.

CA AS DS D CD NA

There ore wo many problems thot 1 find it best

to igrome then and just do my work.

CA AS OS a CD NA

CA a AS DS \& CO NA

I enjoy holping people work out their difficulties. CA DS DS a CO NA

I find myself in ogreement with the odministrotion

in mout mottors.

CA AS DS d CD NA

I om just o poper puaher.

CA A DS d CO NA

I rake raponsibility to be involved in important docisions.

I an highly committed to my work.

CA AS DS d CO NA

I imveriebly do whot the administration wonts wen when I disogree.

CA a AS DS a CO NA

I get tired of listening to other people's problems. CA a AS DS I CO NA

1 con alwon find a woy to bend the rules to make work os cony as posible.

I feal like a creotive human being when I an of work.

CA AS DS a CO NA

I an alwoys in some kind of quarrol with the odministrotion.

1 go to a lot of workshope in the hope thet I will lecen something to moke $\mathrm{my}$ work cesier.

1 don't feel very involved in my work.

CA AS OS d CD NA

I am emberrened to odmit what 1 do for a living.

CA a AS DS d CO NA

Othen should worry chout the need of clients

at much os I do.

I do whor's necency and litrle more.

CA A DS a CD NA

CA AS DS a CO NA

CA a AS DS a CO NA

When things ore not right I ol wom piteh in to heip work thing out.

If I hod to do it oree, I would ehoon this iob/ cereer over ogsin.

CA a AS DS a CD NA

CA a DS a CD NA

CA a AS DS a CD NA

CA a AS OS C CD NA

I like to work with others in the hope of improving the wociel urvices.

Too many people diefors how my work is to be corried out.

I feal I en port of a real nem.

CA a OS a CO NA CA a AS DS a CD NA ca o AS DS a CO NA

I hove ny oree of expertien and an not concerned by what others or doing.

My job is strietly a meons to an econemic end. CA a DS $\mathrm{C}$ CD NA 


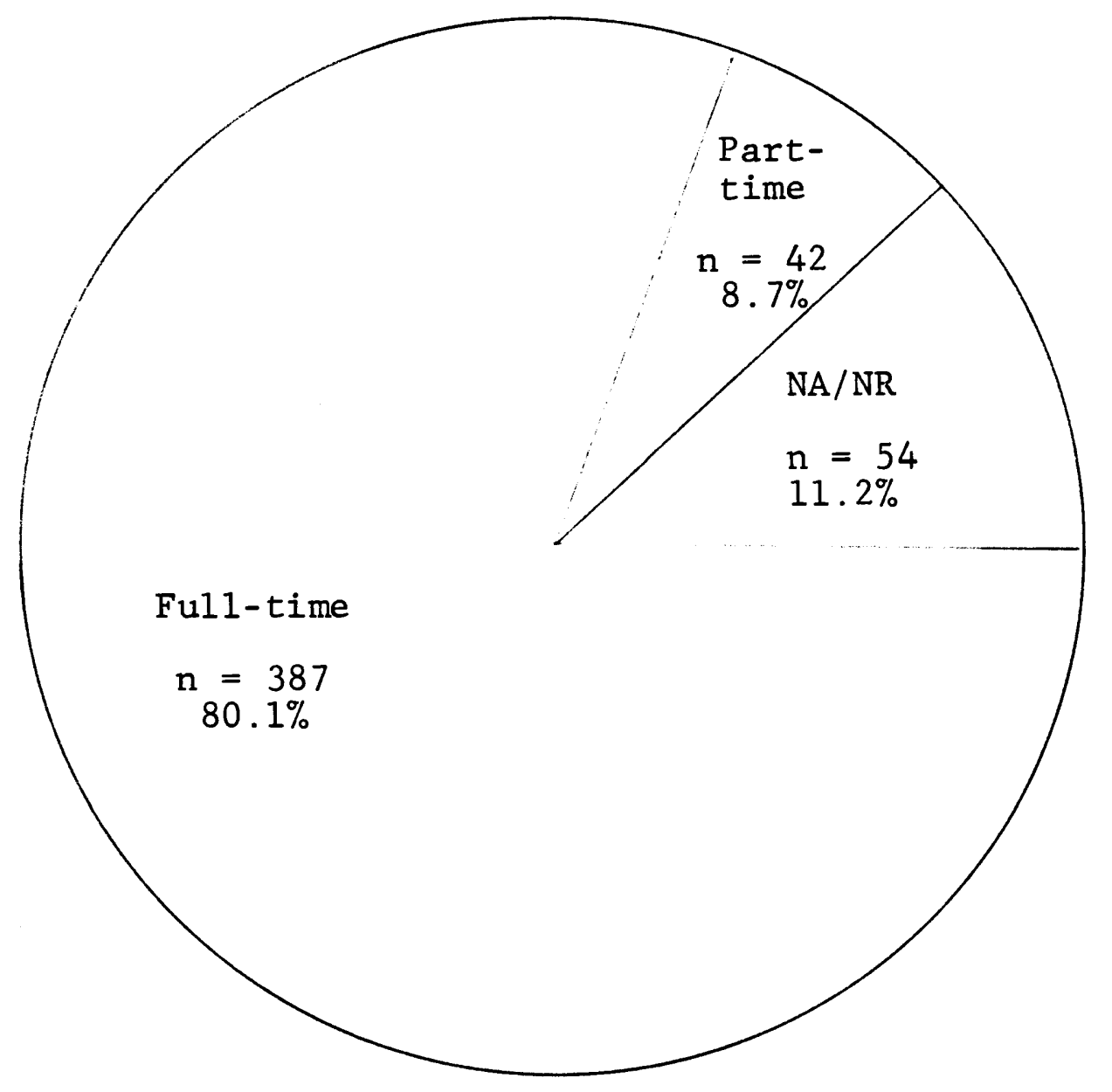

Figure 4. Ful1- or part-time employment in social services. 
TABLE XXIII

AGE OF RESPONDENTS

\begin{tabular}{ccc}
\hline Age & $\begin{array}{c}\text { Number of } \\
\text { Respondents }\end{array}$ & Percent \\
\hline $0-25$ & 15 & 3.1 \\
$26-30$ & 67 & 13.9 \\
$31-35$ & 100 & 20.7 \\
$36-40$ & 92 & 19.9 \\
$41-45$ & 42 & 10.1 \\
$46-50$ & 36 & 7.5 \\
$51-55$ & 59 & 12.2 \\
$56-$ above & 45 & 9.3 \\
NR & 20 & 4.1 \\
Totals & 483 & 100.0 \\
\hline
\end{tabular}

TABLE XXIV

LENGTH OF TIME EMPLOYED IN SOCIAL SERVICES

\begin{tabular}{rrr}
\hline \hline $\begin{array}{c}\text { Number of } \\
\text { Years }\end{array}$ & $\begin{array}{c}\text { Number of } \\
\text { Respondents }\end{array}$ & Percent \\
\hline 1 to 4 & 72 & 14.9 \\
5 to 8 & 119 & 24.6 \\
9 to 12 & 99 & 20.5 \\
13 to 16 & 77 & 15.9 \\
17 to 20 & 28 & 5.8 \\
21 to 24 & 20 & 4.1 \\
25 to 28 & 18 & 3.6 \\
29 to 32 & 21 & 4.3 \\
33 to 36 & 4 & 1.2 \\
37 and above & 10 & 2.0 \\
NR & 15 & 3.1 \\
Totals & 483 & 100.0 \\
\hline
\end{tabular}


TABLE XXV

LENGTH OF TIME EMPLOYED AT PRESENT POSITION

\begin{tabular}{ccc}
\hline $\begin{array}{c}\text { Number of } \\
\text { Years }\end{array}$ & $\begin{array}{c}\text { Number of } \\
\text { Respondents }\end{array}$ & Percent \\
\hline 1 to 3 & 220 & 45.5 \\
4 to 6 & 115 & 23.8 \\
7 to 9 & 57 & 11.8 \\
10 to 12 & 44 & 9.1 \\
13 to 15 & 9 & 1.9 \\
16 to 18 & 9 & 1.9 \\
19 to 21 & 6 & 1.2 \\
22 to 24 & 1 & .2 \\
25 and above & 7 & 1.4 \\
NR & 15 & 3.2 \\
Total & 483 & 100.0 \\
\hline
\end{tabular}

